Copyright

by

Yirui Liang

2010 
The Thesis Committee for Yirui Liang

Certifies that this is the approved version of the following thesis:

\title{
Indoor Residential Fate Model of Phthalate Plasticizers
}

\author{
APPROVED BY \\ SUPERVISING COMMITTEE:
}

Supervisor:

$$
\text { Ying Xu }
$$

Richard Corsi 


\title{
Indoor Residential Fate Model of Phthalate Plasticizers
}

by

Yirui Liang, B.S.

\author{
Thesis \\ Presented to the Faculty of the Graduate School of \\ The University of Texas at Austin \\ in Partial Fulfillment \\ of the Requirements \\ for the Degree of
}

Master of Science in Engineering

The University of Texas at Austin

December 2010 


\section{Dedication}

To my parents 


\section{Acknowledgements}

I am sincerely thankful for my advisor, Dr. Ying $\mathrm{Xu}$, whose guidance, support and encouragement from the beginning to the end enabled me to develop an understanding of the subject and accomplish the thesis with satisfaction. Also, I would like to thank Dr. Corsi, who offered me great suggestions during the completion of the thesis.

I owe my deepest gratitude to my parents who always supported me, understood me and helped me in every possible way. Also, I would like to thank my girlfriend, Shuwen $\mathrm{Gu}$, who supported and encouraged me at all times.

December 2010 


\title{
Abstract \\ Indoor Residential Fate Model of Phthalate Plasticizers
}

\author{
Yirui Liang, M.S.E. \\ The University of Texas at Austin, 2010
}

Supervisor: Ying Xu

\begin{abstract}
A three-compartment model is extended to estimate the fate and transport of DEHP in a realistic residential environment. The model considered eight environmental media (i.e. air, particulate matter with six size fractions, vinyl flooring, carpet, furniture, dust, wall and ceiling). Particle movement (deposition and resuspension), dust removal (vacuuming), indoor cooking, and adsorption/absorption on indoor surfaces are included. The predicted airborne DEHP concentrations at steady state are within $0.1 \mu \mathrm{g} / \mathrm{m}^{3}$ to 0.6 $\mu \mathrm{g} / \mathrm{m}^{3}$, which are similar to those measured in field studies. After vinyl flooring (the primary source) is removed, it takes 2 years for the indoor airborne DEHP level to reduce $0.01 \mu \mathrm{g} / \mathrm{m}^{3}$, and the time increases significantly when carpet present. The results indicate that carpets as well as other interior surfaces may be important phthalate sinks and if the only removal mechanism is ventilation, strongly sorbing phthalate may persist for years. Phthalate amount in dust is strongly influenced by the deposition surface. The vi
\end{abstract}


concentration of DEHP presents 10 times higher in dust on the source (vinyl flooring) than on the sink (furniture), and it takes more than a year for DEHP to reach equilibrium between bulk air and dust. The domestic activity of cooking is then included in the model and it shows that suspended particle concentration has a substantial impact on gas-phase DEHP level indoors, while the influence of ventilation is only to some extent. Three other SVOCs (DMP, BBP and DiDP) are also investigated and their environmental fates show that chemical's vapour pressure and octanol/air partition coefficient have substantial influences on sorbing mechanisms and the gas phase and airborne concentrations. 


\section{Table of Contents}

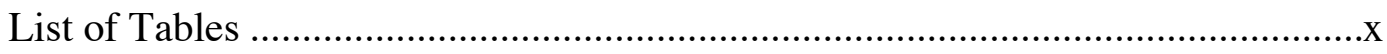

List of Figures ........................................................................................

List of Illustrations .............................................................................. xiii

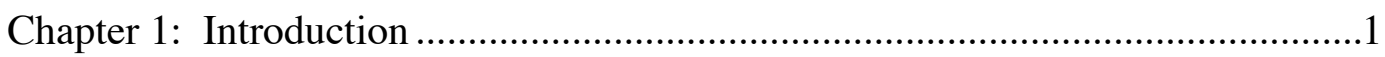

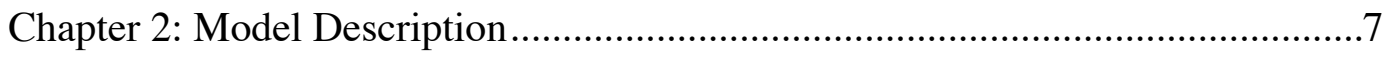

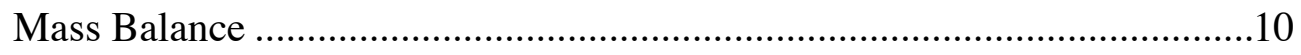

Emissions of DEHP from Vinyl Flooring ..................................................14

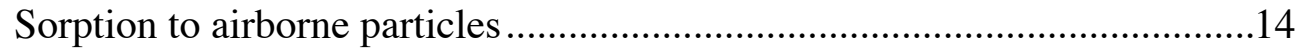

Partitioning between gas phase and settled dust ......................................16

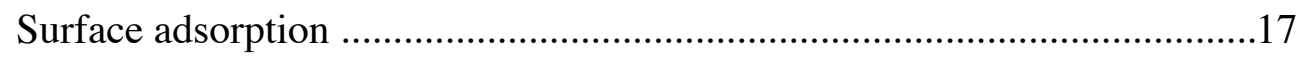

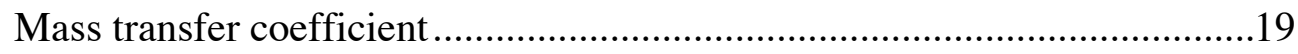

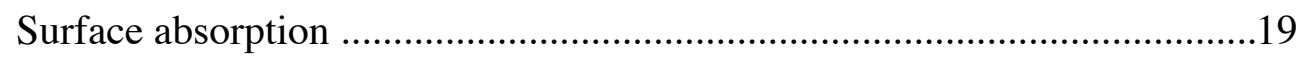

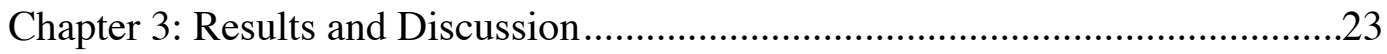

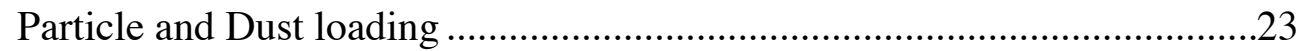

Gas phase and airborne DEHP concentration .........................................26

DEHP on interior surfaces ..................................................................28

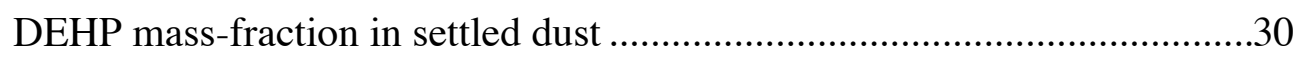

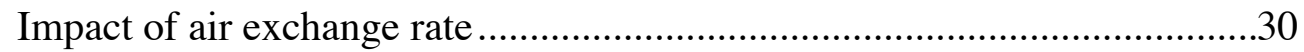

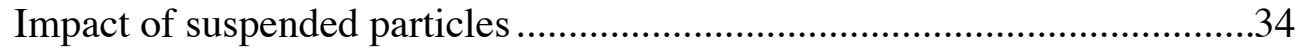

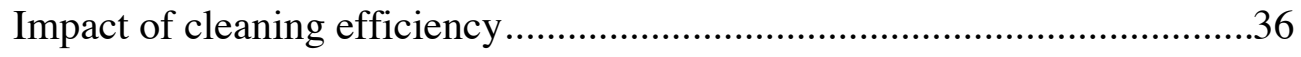

Removing DEHP source after a period of time .........................................37

Cooking as an indoor particle source .......................................................39

Indoor environmental fates of various phthalates ...................................41 


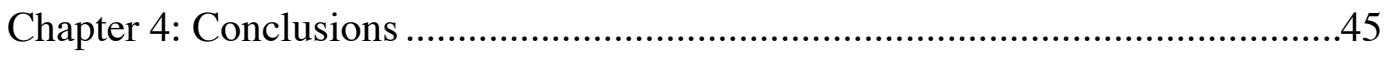

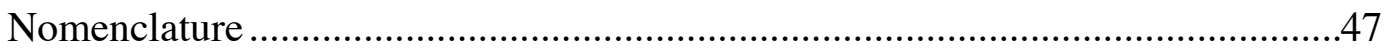

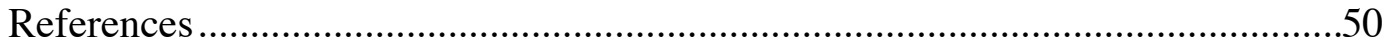

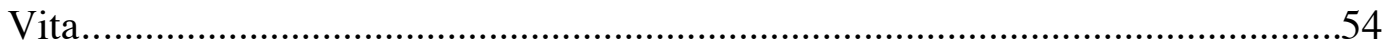




\section{List of Tables}

Table 1: Conditions for the three-compartment residential model.....................8

Table 2: $\quad$ Particle properties and deposition velocities. ...................................12

Table 3: Modeling parameters for cooking activities. ..................................13

Table 4: Properties for carpet absorption of DEHP......................................21

Table 5: Physical and sorption properties of phthalates ...............................22

Table 6: Predicted indoor air DEHP concentration compared with those cited in

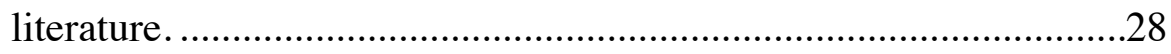

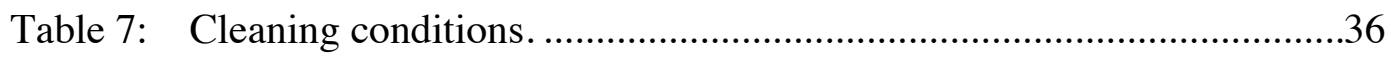




\section{List of Figures}

Figure 1: TSP concentrations in each compartment. .....................................24

Figure 2: Dust loading in the main house................................................25

Figure 3: The gas phase DEHP concentrations in each compartment...............27

Figure 4: The airborne DEHP concentrations in each compartment. ................27

Figure 5: Surface DEHP concentrations in the kitchen. ................................29

Figure 6: DEHP concentration on interior surfaces in the main house..............29

Figure 7: Predicted mass-fraction in settled dust on the wall and field studies..30

Figure 8: Indoor TSP concentrations under different air exchange rates in the main

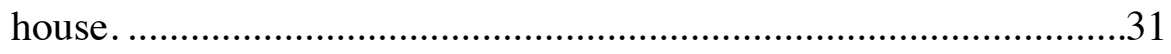

Figure 9: Impact of air exchange rate on the gas phase DEHP in the main house.32

Figure 10: Impact of air exchange rate on the airborne DEHP in the main house.32

Figure 11: Impact of air exchange rate on DEHP on wall surface in the main house.

Figure 12: Impact of air exchange rate on DEHP on carpet in the main house..33

Figure 13: Indoor TSP concentrations in Houston and Beijing.........................34

Figure 14: Gas phase DEHP concentrations in the main house in Houston and Beijing .35

Figure 15: Airborne DEHP concentrations in the main house in Houston and Beijing. .35

Figure 16: DEHP on the carpet under different cleaning conditions..................37

Figure 17: The gas phase DEHP concentration in the main house.....................38

Figure 18: The airborne DEHP concentration in the main house......................38

Figure 19: DEHP on the wall surface in the main house.................................39 
Figure 20: Gas phase DEHP concentrations in each compartment. ..................40

Figure 21: Airborne DEHP concentrations in each compartment. ....................40

Figure 22: Gas phase SVOC concentration in the main house..........................41

Figure 23: Airborne SVOC concentration in the main house............................42

Figure 24: Surface DEHP concentration on the wall in the main house. ...........43

Figure 25: Surface SVOC concentration on carpet in the main house. ..............44 


\section{List of Illustrations}

Illustration 1: Schematic representation of the three-compartment residential house.

Illustration 2: Schematic of sorption process for nonporous surface. Note that the three individual materials shown for illustrative purposes and do not comprise a layered structure. .18

Illustration 3: Schematic of absorption process of carpet.................................20 


\section{Chapter 1: Introduction}

Modern indoor environments contain a vast array of materials and products, many of which emit harmful contaminants (Weschler et al. 2009). Emissions from these sources produce indoor concentrations that are substantially higher than outdoors (Rudel and Perovich 2009). Since the 1950s, levels of some indoor pollutants (formaldehyde, aromatic and chlorinated solvents, chlorinated pesticides and polychlorinated biphenyls (PCBs)) have increased and then decreased. In contrast, levels of phthalate plasticizers and brominated flame-retardants (polybrominated diphenyl ethers (PBDEs)) have increased and remain high (Weschler 2009; Rudel and Perovich 2009). These semivolatile organic compounds (SVOCs) are used as additives to enhance performance and are often present in the product at percent to tens-of-percent level (Clausen et al. 2004; Xu and Little 2006; Weschler and Nazaroff 2008; Chen et al. 2009; Stapleton et al. 2009). For example, polyvinyl chloride (PVC) flooring typically contains $30 \%$ to $40 \%$ by mass phthalate plasticizer (Bornehag et al. 2005).

Since 1930s, phthalates have been increasingly used as plasticizers to enhance the flexibility of rigid PVC products (Latini et al. 2004). The global production rate of phthalates has increased from 2.5 million tons/year to 6 million tons/year within a decade (Cadogan et al. 1996; SRI 2007). About $90 \%$ of phthalates are used as plasticizers in polymers (e.g., PVC) and are found in a wide range of consumer products including floor and wall covering, toys, car interior trim, electrical cable insulation, clothing, gloves, footwear, and artificial leather (Uhde et al., 2001; Clausen et al. 2004; Bornehag et al. 2005; Xu et al. 2009). Recently, the use of several phthalates in children's articles has been restricted in EU and US because of the emerging concerns on their potential health effects (Scott, 2005). As a result, phthalates used in PVC products are changing rapidly, 
with manufacturers substituting high molecular weight phthalates, such as di-iso-nonylphthalate (DINP) and di-iso-decyl-phthalate (DIDP), for low molecular weight ones, such as di-butyl-phthalate (DBP) and di-(2-ethylhexyl)-phthalate (DEHP) (ECPI 2009). Currently, DEHP, DINP and DIDP are the most widely used phthalates and accounts for more than $80 \%$ of total phthalate production (SRI 2007; Bisig 2009; ECPI 2009).

Because phthalates are not chemically bound in polymers, they are easily released from products into the environment. In the outdoor environment, phthalates may be subject to photo degradation, biodegradation or anaerobic degradation and thus generally do not persist (Rudel and Perovich 2009). While in the indoor environment, they are ubiquitous, redistributing from their original source to indoor air and all interior surfaces including airborne particles, dust, and skin (Xu et al. 2009 and 2010a). Because they partition so strongly to surfaces, many phthalates persist for years after the source is removed (Weschler and Nazaroff 2008). By measuring dustborne and airborne phthalates in residential houses, numerous studies revealed that phthalates are one of the most abundant contaminants indoors (Rudel et al. 2003; Fromme et al. 2004 and 2009; Morgan et al. 2004; Weschler et al. 2008; Kanazawa et al. 2010). In the recent study of children's total exposure to persistent pollutants (CTEPP), concentrations of over 50 target compounds were measured in homes and daycare centers of 260 pre-school children (EPA 2005). The two phthalates targeted in the CTEPP study were detected in residential air and house dust, and on a range of interior surfaces and dermal wipe samples. The measured phthalate concentrations were amongst the highest of any of the target compounds (including pesticides, PAHs and PCBs) and were generally higher on human skin than on all other surfaces (Xu et al. 2009 and 2010a).

The serious adverse health effects of phthalate esters and their metabolites are detailed in several recent reviews (Heudorf et al. 2007; Jaakkola and Knight 2008; Latini 
et al. 2006; Matsumoto et al. 2008; McKee et al. 2004; Ritter and Arbuckle 2007). Collectively, these reviews show that exposure to some phthalates results in profound and irreversible changes in the development of the reproductive tract, especially in males. It has even been suggested that phthalates could be the leading cause of reproductive disorders in humans (Latini et al. 2006). Effects such as increases in prenatal mortality, reduced growth and birth weight, and skeletal, visceral, and external malformations, are also associated with exposure to phthalates. In addition, a possible correlation between phthalate plasticizer exposure and asthma and airway diseases in children has recently been discovered based on epidemiological data (Bornehag et al. 2004; Kolarik et al. 2008; Larsson et al. 2009; Bornehag and Nanberg 2010). Experiment studies (Oie et al. 1997; Lagercrantz et al. 2005) have shown that inhalation exposures to even low levels of phthalates may cause lung inflammation through their chemical similarity to prostaglandins, naturally occurring inflammatory agents. Other in vivo and in vitro studies also supported the adjuvant effects on basic mechanisms in allergic sensitization by several phthalates (Larsen et al. 2004 and 2007; Hansen et al. 2007; Yang et al. 2008; Bornehag et al. 2010). Furthermore, certain phthalates have chemical structures that are similar to those of human hormones and can either mimic or block endocrine activity (Sharp 2005; Bornehag et al. 2010). These endocrine disrupters have been suggested as potential contributors to neurodevelopment and behavioral problems ranging from autism to attention deficit disorder (Weschler and Nazaroff 2008). Heudorf et al. (2007) estimate that effective intake of phthalates is higher in children than in adults, although data are not available for children less than 3 years of age. Exposure during development (in utero, infants and children) is of special concern, because developing tissues are exquisitely sensitive to endocrine signals and disruption of these signaling pathways can 
result in permanent alterations in tissue structure and function (Rudel and Perovich 2009).

Concentrations of phthalate metabolites measured in the general population using biomonitoring methods (blood and urine) provide direct evidence of wide-spread human exposure (Calafat and McKee 2006; Heudorf et al. 2007). Biomonitoring data based on blood suggest that over 75\% of the US population is exposed to phthalates (Silva et al. 2004). When urinary concentrations of secondary metabolites are measured, the estimate increases to 95\% (Kato et al. 2004). Therefore, an urgent need exists to identify the most important sources and pathways of exposure (NRC 2006). However, exposure to phthalates is difficult to evaluate because phthalates are so ubiquitous and because phthalate concentration measurements are hampered by contamination (Koch et al. 2003). To complicate matters, phthalates are sorbed strongly to surfaces, as do other SVOCs such as biocides and flame retardants (Weschler and Nazaroff 2008). A relatively small gas-phase concentration, such as $0.1 \mathrm{ppb}$, is sufficient for meaningful vapor transport of a phthalate ester and its consequent partitioning between the gas phase and indoor surfaces, including airborne particles and settled dust (Weschler 2003). Adibi et al. (2008) measured phthalate metabolite concentrations in urine samples from 246 pregnant women and correlated these with indoor air concentrations. They concluded that a single indoor air sample may be sufficient to characterize phthalate exposure in the home.

Xu et al. (2009 and 2010a) have proposed a simple approach that can be used to identify the most important sources of phthalate exposure. They (Xu and Little 2006) showed that emissions of these very low volatility compounds are subject to "external" control (partitioning from the material into the gas phase, convective mass transfer through the boundary layer, and strong sorption onto interior surfaces including airborne particles). Using data collected in a specially-designed stainless steel chamber, they 
showed that the emission rate of DEHP from vinyl flooring can be predicted based on a priori knowledge the gas-phase concentration of DEHP in equilibrium with the materialphase, the material to air and air to stainless steel surface mass-transfer coefficients, and the stainless steel/air equilibrium relationship (Xu et al. 2010b). This chamber-based model was extended to predict human exposures to DEHP emitted from vinyl flooring in a realistic residential environment (Xu et al. 2009 and 2010a) using the CTEPP data to establish surfaces/air partition coefficient values for dust and other interior surfaces. Based on Xu et al.'s model, Liu et al. (2010) investigated the influence of aerosol particles on the accumulation of indoor airborne DEHP by incorporating a variable indoor particle source. However, several challenges still exist for modeling the fate of phthalates indoors. The transport of phthalates caused by indoor particle dynamics has not been clarified. Particles can act as a reservoir for storage of a SVOC compound. Particle deposition and resuspension, dust removal and direct indoor particle emissions will cause redistribution of phthalates between air-, particle- and surface- phase, and thus play essential roles in the transport of phthalates indoors. Although studies are available on the equilibrium partition between air and indoor surfaces such as vinyl flooring, hard floor and particles (Xu et al. 2009; Weschler and Nazaroff 2008), the air boundary layer adjacent to the sorbing surfaces may act as a resistance for equilibrium to be reached. Therefore, a thorough investigation is needed on the sorption kinetics. In addition, phthalates can be taken up by indoor materials such as carpet and then re-emitted into the air. As such, these materials can act as buffers for indoor phthalate concentrations, modulating and prolonging their presence (Zhang et al. 2009). Although insufficient data are available to develop models that account for the diffusion into all interior surfaces, it is necessary to study the diffusion of phthalates into porous materials. 
In this research, we extend $\mathrm{Xu}$ et al. model to investigate the fate and transport of phthalate plasticizers in residential environment. Our goal was to (1) predict the indoor fate of DEHP with the consideration of particle sizes and dynamics, sorption kinetics and diffusion into porous materials; (2) describe the sink/source behavior of indoor goods and materials; (3) identify factors that influence the transport of DEHP indoors including indoor cooking, cleaning frequency, ventilation, removal of sources and outdoor air quality; (4) extend study to a range of phthalates including DMP, BBP, DINP and DIDP. 


\section{Chapter 2: Model Description}

Building upon previous models (Xu and Little 200d6; Xu et al. 2009 and 2010; Liu et al. 2010), the indoor residential fate model of phthalate plasticizers is a dynamic mass-balance model with several compartments and multimedia simultaneously exchanging mass. The model considers airborne phthalates with input from indoor sources, resuspended particles, and desorption from interior surfaces. Losses occur through air advection, particle deposition, dust removal, and phthalate transport to surfaces. As shown in Figure 1, DEHP is emitted from vinyl flooring in a residential house, which is divided into three compartments: kitchen, bathroom and the main house. The gas-phase DEHP is sorbed on interior surfaces, including walls, ceiling, wood floor, furniture, windows, tile, ceramic fixtures, and particles through partitioning mechanisms. Particle deposition and resuspension that may further accelerate the mass transfer between sources and sinks are included in this model. In addition to sorptive partitioning to interior surfaces, phthalates can also diffuse into the porous materials (e.g. carpet) and sorb there. Over time, such processes may establish important reservoirs and thus is included. We obtained the infiltration/exfiltration rates and ventilation rates between rooms shown in Table 1 from measurements made by Wilkes et al. (1992) in a five-room house. We estimated the interior surface area of furnishing and materials using typical surface/volume ratios for American houses established by Hodgson et al. (2005) (Table $1)$. 


\begin{tabular}{llll}
\hline Compartment & Kitchen & Bathroom & Main house \\
\hline Volume $\left(\mathrm{m}^{3}\right)$ & 35 & 15 & 128 \\
Surface area $\left(\mathrm{m}^{2}\right)$ & & & \\
Vinyl flooring & 14.4 & 6.20 & 19.2 \\
Ceiling & 14 & 6 & 51.2 \\
Walls & 20 & 17.3 & 72.8 \\
Carpet & - & - & 35.8 \\
Wood floor & - & - & 32.0 \\
Furniture & 12.6 & 5.40 & 61.4 \\
Windows and mirrors & 1.75 & 1.05 & 5.12 \\
Tile and fixtures & 3.50 & 16.5 & 20.0 \\
\hline
\end{tabular}

Table 1: Conditions for the three-compartment residential model. 


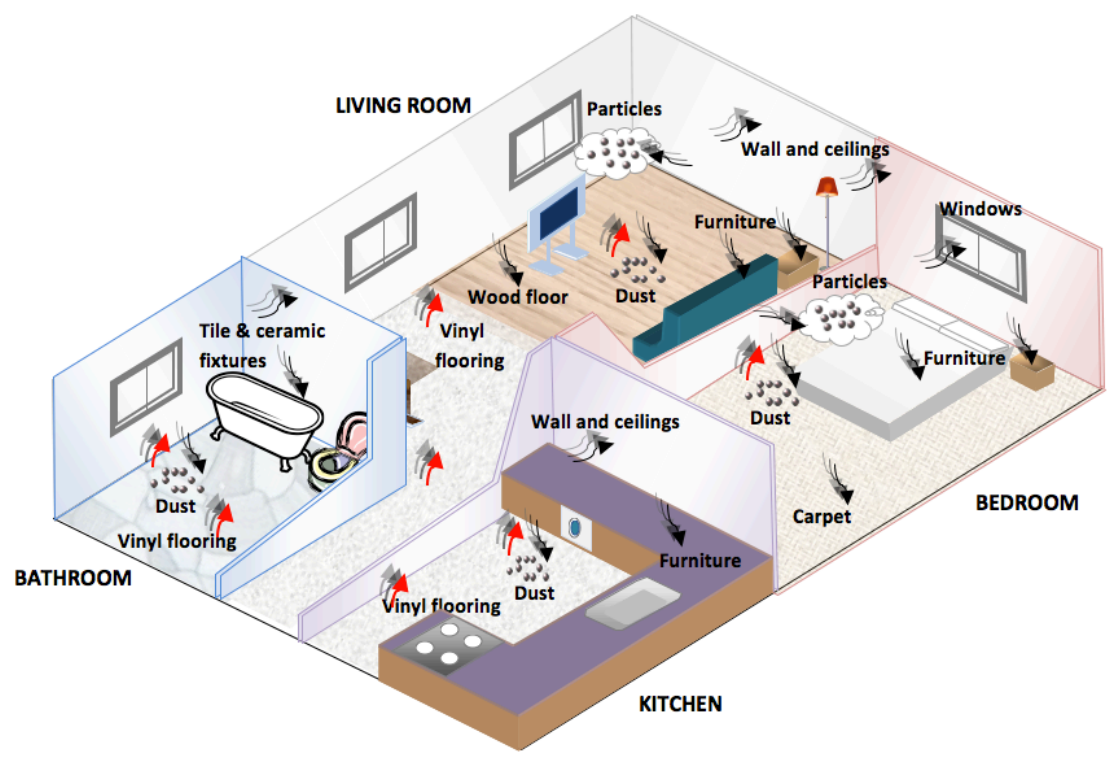

a. DEHP emitting from the vinyl flooring sources and sorbing to the various sinks

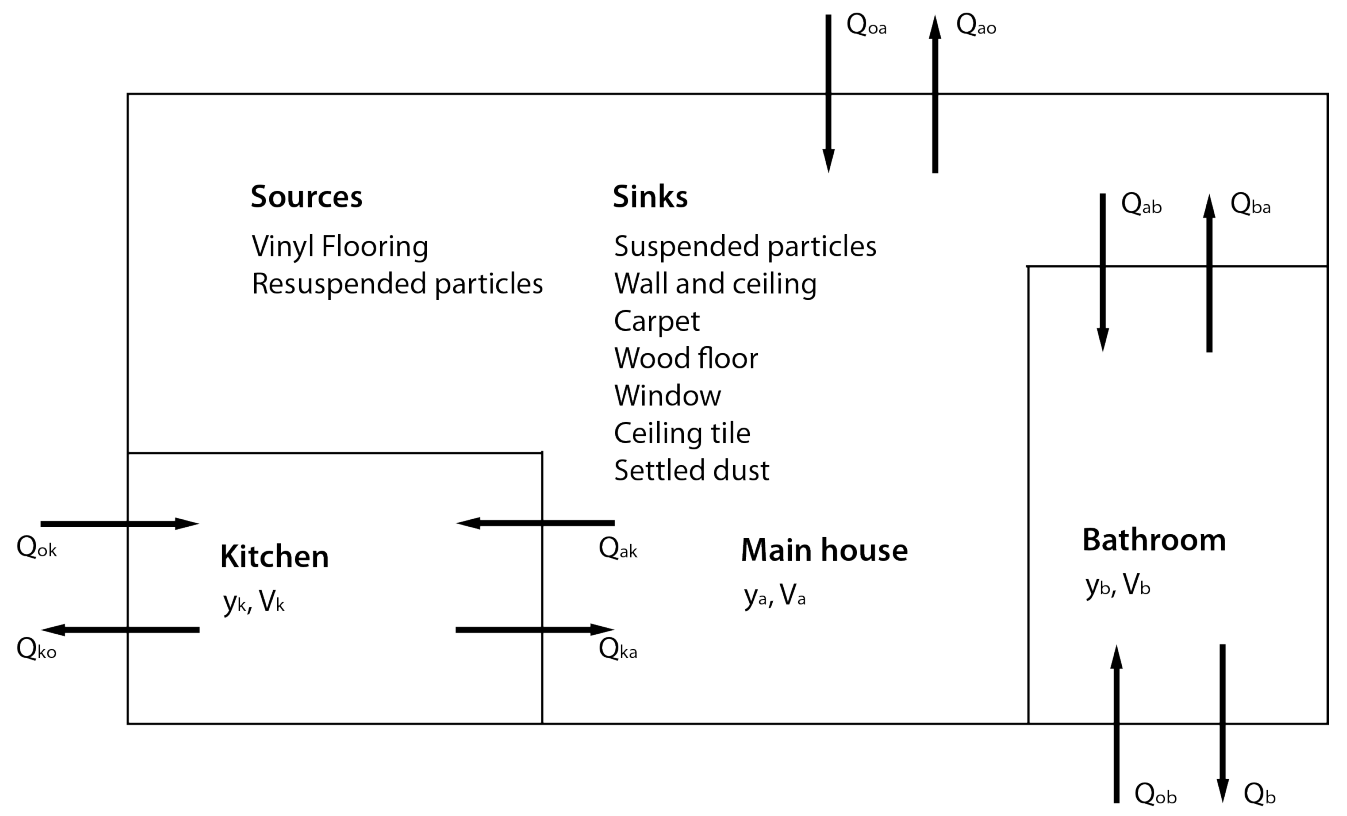

b. Top view of the house showing DEHP sources, sinks and ventilation conditions

Illustration 1: Schematic representation of the three-compartment residential house. 


\section{Mass BalanCe}

With reference to Figure 1, the accumulation of total suspended particles (TSP) in each compartment obeys the following mass balance:

$$
\begin{aligned}
& V_{i} \frac{d T S P_{i}}{d t}=Q_{o i} P_{o} T S P_{\text {outdoor }}-Q_{i o} T S P_{i}+\sum_{j}\left(Q_{j i} \cdot T S P_{j}-Q_{i j} \cdot T S P_{i}\right) \\
& -\sum_{k}\left(\overline{v_{d_{k}}} \cdot T S P_{i} \cdot A_{k}-R_{k} \cdot M_{k} \cdot A_{k}\right)+S_{i}
\end{aligned}
$$

where $\operatorname{TSP}_{\mathrm{i}}\left(\mu \mathrm{g}\right.$ particle $\left./ \mathrm{m}^{3}\right)$ is the total suspended particle concentration in each compartment as a function of time, $\mathrm{V}_{\mathrm{i}}\left(\mathrm{m}^{3}\right)$ is the volume of compartment $\mathrm{i}, \mathrm{Q}_{\mathrm{oi}}$ and $\mathrm{Q}_{\mathrm{io}}$ $\left(\mathrm{m}^{3} / \mathrm{h}\right)$ are infiltration/exfiltration rates between outdoor and compartment $\mathrm{i}, \mathrm{P}_{\mathrm{o}}$ is the sizespecific particle penetration factor, $\mathrm{TSP}_{\text {outdoor }}\left(\mu \mathrm{g}\right.$ particle $\left./ \mathrm{m}^{3}\right)$ is the outdoor particle concentration, $\mathrm{Q}_{\mathrm{ji}}\left(\mathrm{m}^{3} / \mathrm{h}\right)$ is the ventilation rate from compartment $\mathrm{j}$ to $\mathrm{i}, \overline{v_{d_{k}}}(\mathrm{~m} / \mathrm{h})$ is the average size-dependent particle deposition velocity with respect to the $\mathrm{k}^{\text {th }}$ interior surface in compartment $\mathrm{i}$ (e.g., ceiling, wall and floor), $\mathrm{A}_{\mathrm{k}}\left(\mathrm{m}^{2}\right)$ is the area of the $\mathrm{k}^{\text {th }}$ interior surface, $R_{k}\left(h^{-1}\right)$ is the particle resuspension rate for settled dust on the $k^{\text {th }}$ interior surface, $\mathrm{M}_{\mathrm{k}}\left(\mu \mathrm{g}\right.$ particle $\left./ \mathrm{m}^{2}\right)$ is the transient dust loading on the $\mathrm{k}^{\text {th }}$ interior surface and $\mathrm{S}_{\mathrm{i}}(\mu \mathrm{g}$ particle/h) is the source of particles in this compartment.

Following Equation 1, the mass loading on the $\mathrm{k}^{\text {th }}$ surface is controlled by particle deposition and resuspension from the surface, which yields

$$
\frac{d M_{k}}{d t}=\overline{v_{d_{k}}} \cdot T S P_{i}-R_{k} \cdot M_{k}
$$

In our model, size-dependent particle deposition velocity is of importance to determine the suspended particle concentration. The deposition velocities with respect to 
size fractions are listed in Table 2. Additionally, the deposition velocity is also surface orientation dependent. Three different categories of deposition velocities are presented in Table 2, which are vertical downward deposition, horizontal deposition and vertical upward deposition. The vertical and horizontal deposition rates for various particle size fractions are based on field measurements by Bennett and Furtaw (2004). In addition, they calculated indoor particle resuspension rate distribution using the data in Thatcher and Layton (1995) with their assumptions for mass loading of dust on surfaces and the assumption that the homes are occupied on average 8 hour a day. Their estimations are used in this study (Table 2). For a given surface like wall surface, the average particle deposition velocity can be computed through two processes: 1) determine the deposition category, for wall surface, the horizontal deposition should be employed; 2) calculate the average deposition velocity based on mass concentrations of particles of different size fractions. Use $\operatorname{TSP}_{n}$ as the particle concentration with the $\mathrm{n}^{\text {th }}$ size fraction $(1 \leq \mathrm{n} \leq 6), \mathrm{v}_{\mathrm{d}, \mathrm{n}}$ as corresponding deposition velocity, the average deposition velocity with respect to the $\mathrm{k}^{\text {th }}$ surface can be represented as

$\overline{v_{d_{k}}}=\frac{\sum_{n=1}^{6} T S P_{n} \cdot v_{d, n}}{T S P}$

As shown in Equation 1, outdoor particle concentration is one of the important factors governing indoor particle level. A real location with known outdoor air particle concentration and size distribution is thus necessary. Houston, TX, with relatively high levels of fine particles in U.S. (Polidori et al. 2006), was selected and used for most analysis in this study. Although only $\mathrm{PM}_{2.5}$ and $\mathrm{PM}_{10}$ concentrations are available, to more accurately account for indoor particle penetration, deposition and resuspension, as 
shown in Table 2, we estimated particle concentrations in more specific sizes based on trends in field measurements (Riley et al. 2002). Beijing, China was later employed for comparison with the case of Houston. As shown in Table 2, the outdoor particle concentrations of Beijing are two to sixty times higher in each size range than that of Houston. Therefore, the two extremely different background particle levels will allow us to evaluate the influence of outdoor air quality on indoor fate of phthalates.

\begin{tabular}{|c|c|c|c|c|c|c|c|c|}
\hline $\begin{array}{l}\text { size } \\
\text { fraction } 1\end{array}$ & $\begin{array}{l}\text { fraction } \\
\text { of } \\
\text { organic } \\
\text { carbon }^{2}\end{array}$ & $\begin{array}{l}\text { pene- } \\
\text { tration } \\
\text { ratio }\end{array}$ & $\begin{array}{l}\text { vertical } \\
\text { downward } \\
\text { deposition } \\
\text { velocity }^{2} \\
(\mathrm{~m} / \mathrm{h})\end{array}$ & $\begin{array}{l}\text { horizontal } \\
\text { deposition } \\
\text { velocity }^{2} \\
(\mathrm{~m} / \mathrm{h})\end{array}$ & $\begin{array}{l}\text { vertical } \\
\text { upward } \\
\text { deposition } \\
\text { velocity }^{2} \\
(\mathrm{~m} / \mathrm{h})\end{array}$ & $\begin{array}{l}\text { re- } \\
\text { suspension } \\
\text { coefficient } 1 \\
\left(\mathrm{~h}^{-1}\right)\end{array}$ & $\begin{array}{l}\text { outdoor cc } \\
\left(\mu \mathrm{g} / \mathrm{m}^{3}\right)\end{array}$ & entration \\
\hline $0-1$ & & & 0.3 & $3.2 \times 10^{-3}$ & $3.6 \times 10^{-5}$ & $1.1 \times 10^{-7}$ & 12.7 & 25.7 \\
\hline $1-2.5$ & 0.30 & 0.74 & 1. & & negligible ${ }^{c}$ & $4.6 \times 10^{-7}$ & 6.8 & 60 \\
\hline $2.5-10$ & 0.30 & 0.4 & 2.7 & & negligible & $6.8 \times 10^{-6}$ & 14.3 & 63.5 \\
\hline $10-65$ & 0.20 & 0 & $2.7 \times 10^{2}$ & $1.8 \times 10^{-5}$ & negligible & $2.9 \times 10^{-5}$ & 40 & 80.1 \\
\hline $65-150$ & 0.15 & 0 & $2.7 \times 10^{3}$ & $3.6 \times 10^{-6}$ & negligible & $4.2 \times 10^{-6}$ & 30.1 & 57.6 \\
\hline $150-2000$ & 0.05 & 0 & $2.7 \times 10^{4}$ & $3.6 \times 10^{-8}$ & negligible & $4.2 \times 10^{-6}$ & 0 & 62.3 \\
\hline
\end{tabular}

Table 2: $\quad$ Particle properties and deposition velocities.

In our baseline calculations, no indoor particle source was included in each compartments, so in Equation 1, the source term (i.e. $\mathrm{S}_{\mathrm{i}}$ ) equals zero. In later calculations, we also considered particle emissions from cooking in the kitchen to investigate the influence of indoor particle emissions on DEHP concentrations. The particle emission rate for cooking, as denoted by $\mathrm{S}_{\mathrm{p}, \text { cook }}$, and size fraction were determined based on study by Buonanno et al. (2009). The modeling parameters for cooking activities are listed in Table 3.

\footnotetext{
${ }^{1}$ Bennett and Furtaw (2004).

2 Lai and Nazaroff (2002).

3 TCEQ (Texas Commission on Environmental Quality) 2010.

${ }^{4} \mathrm{Hao}$ and Wang (2006).
} 


\begin{tabular}{l|llllll}
\hline Size fraction $(\mu \mathrm{m})$ & $0-1$ & $1-2.5$ & $2.5-10$ & $10-65$ & $65-150$ & $150-2000$ \\
Mass fraction $(\%)$ & 76 & 24 & 0 & 0 & 0 & 0 \\
$\mathrm{~S}_{\mathrm{p}, \text { cook }}(\mathrm{mg} / \mathrm{hr})$ & 54.72 & 17.28 & 0 & 0 & 0 & 0 \\
\hline
\end{tabular}

Table 3: $\quad$ Modeling parameters for cooking activities.

The accumulation of airborne DEHP concentration in each compartment obeys the following mass balance:

$$
\begin{aligned}
V_{i} \frac{d y_{i}}{d t}+V_{i} \frac{d F_{i}}{d t} & \\
& =Q_{o i}\left(y_{\text {outdoor }}+F_{\text {outdoor }}\right)-Q_{i o}\left(y_{i}+F_{i}\right)+\sum_{j} Q_{j i} \cdot\left(y_{j}+F_{j}\right) \\
& -\sum_{j} Q_{i j}\left(y_{i}+F_{i}\right)-\sum_{k}\left[\overline{v_{d_{k}}} \cdot F_{i} \cdot A_{k}+h_{m, k}\left(y_{j}-y_{0, \text { surf }_{k}}\right) \cdot A_{k}\right. \\
& \left.-X_{\text {dust }_{k}} \cdot R_{k} \cdot M_{k} \cdot A_{k} \cdot y_{0, \text { surf }_{k}}\right]
\end{aligned}
$$

where $\mathrm{y}_{\mathrm{i}}\left(\mu \mathrm{g} \mathrm{DEHP} / \mathrm{m}^{3}\right)$ is the DEHP concentration in the $\mathrm{i}$-th compartment as a function of time, $\mathrm{y}_{\text {outdoor }}\left(\mu \mathrm{g} \mathrm{DEHP} / \mathrm{m}^{3}\right)$ is the outdoor DEHP concentration, $\mathrm{F}_{\mathrm{i}}\left(\mu \mathrm{g} \mathrm{DEHP} / \mathrm{m}^{3}\right)$ is the particle-phase DEHP concentration in the compartment $\mathrm{i}, \mathrm{F}_{\text {outdoor }}\left(\mu \mathrm{g} \mathrm{DEHP} / \mathrm{m}^{3}\right)$ is the outdoor particle-phase DEHP concentration, $\mathrm{h}_{\mathrm{m}, \mathrm{k}}(\mathrm{m} / \mathrm{h})$ is the mass transfer coefficient for the boundary layer adjacent to the various surfaces, $\mathrm{y}_{0, \operatorname{surf}_{\mathrm{k}}}\left(\mu \mathrm{g} \mathrm{DEHP} / \mathrm{m}^{3}\right)$ is the gasphase DEHP concentration at interface of air and the $\mathrm{k}^{\text {th }}$ interior surface, $\mathrm{X}_{\text {dust }_{\mathrm{k}}}$ (ug DEHP/ug particle) is the mass-fraction of DEHP in settled dust on the $\mathrm{k}^{\text {th }}$ interior surface. Phthalates are subject to photochemical degradation, oxidation and hydrolysis and thus generally do not persist in the outdoor environment (Weschler and Nazaroff 2008; Rudel and Perovich 2009). Therefore, it is reasonable to assume $\mathrm{y}_{\text {outdor }}$ and $\mathrm{F}_{\text {outdoor }}$ equal to zero.

\footnotetext{
${ }^{1}$ The total particle emission rate for cooking is $72 \mathrm{mg} / \mathrm{hr}$.
} 


\section{EMISSIONS OF DEHP FROM VINYL FLOORING}

DEHP emission rate is mainly dominated by "exterior" conditions such as mass transfer through boundary layer and sorption to various surfaces (Xu and Little 2006). With a high mass concentration (40\% w/w), DEHP is emitted from vinyl flooring very slowly due to its low volatility. In fact, calculations show that even after 1 year only $0.003 \%$ of the total mass of DEHP has come out of the vinyl flooring (Xu et al. 2009). Therefore, the DEHP concentration in vinyl flooring is assumed to remain constant and diffusion of DEHP inside vinyl flooring is ignored. Thus, the emission rate can be described as:

$\dot{m}(t)=h_{m} \cdot\left(y_{0}-y\right)$

where $\mathrm{y}_{0}\left(\mu \mathrm{g} \mathrm{DEHP} / \mathrm{m}^{3}\right)$ is the DEHP concentration in the boundary layer immediately adjacent to the top of vinyl flooring. It can be estimated based on a linear relationship between material-phase DEHP concentration and gas-phase concentration in the adjacent air, which is:

$y_{0}=C_{0} /_{K}$

where $\mathrm{C}_{0}\left(\mathrm{ug} \mathrm{DEHP} / \mathrm{m}^{3}\right)$ is the constant DEHP concentration in vinyl flooring and $\mathrm{K}$ is the vinyl flooring/air DEHP partition coefficient.

\section{SORPTION TO AIRBORNE PARTICLES}

For suspended particles, the distribution of an organic compound between the gas phase and the surface of the airborne particles is described by an equilibrium constant 
referred to as the particle/gas partition coefficient, $\mathrm{K}_{\mathrm{pg}}\left(\mathrm{m}^{3} / \mu \mathrm{g}\right.$ particles) (Pankow et al. 1992):

$K_{p g}=\frac{F / T S P}{y}$

where $\mathrm{F}\left(\mu \mathrm{g} / \mathrm{m}^{3}\right)$ is the equilibrium particle phase concentration of the compound, $\mathrm{y}$ $\left(\mu \mathrm{g} / \mathrm{m}^{3}\right)$ is the equilibrium gas-phase concentration of the compound and TSP $(\mu \mathrm{g}$ particles $/ \mathrm{m}^{3}$ ) is the mass concentration of total suspended particles. F/TSP is the fractional concentration of a given organic compound on particles (e.g., $\mu \mathrm{g} \mathrm{DEHP/g}$ particles). As noted by Weschler and Nazaroff (2008), within-particle diffusion can smooth internal concentration gradients within minutes. Hence, the internal diffusion of phthalate within particles is ignored. Compared to the rate of mass transfer to a large flat surface, the rate for external mass transfer through the air immediately surrounding the particle is inherently fast. The time scale for equilibrium sorption to particles is thus short $(0.1 \mathrm{~s} \sim 1 \mathrm{~d})$, which means that the assumption of an instant equilibrium sorption for phthalates to suspended particles is reasonable (Weschler and Nazaroff 2008). The equilibrium partition coefficient between particle-phase and gas-phase, $\mathrm{K}_{\mathrm{pg}}\left(\mathrm{m}^{3} / \mu \mathrm{g}\right.$ particles) can be estimated by:

$K_{p g}=\frac{f_{o m_{-} \text {part }} \times K_{o a}}{\rho_{\text {part }}}$

where $f_{\text {om_part }}$ is the fraction of suspended particles that is organic matter, $\mathrm{K}_{\mathrm{oa}}$ is the octanol/air partition coefficient and $\rho_{\text {part }}\left(\mu \mathrm{g} \mathrm{dust} / \mathrm{m}^{3}\right)$ is the density of suspended particles. The size-specific fraction of organic matter values were determined based on 
trends in outdoor levels (Bennett and Furtaw 2004). These values along with all other properties for particulate matter are listed in Table 2. The octanol/air partition coefficient, $\mathrm{K}_{\mathrm{oa}}$, for a phthalate ester can be calculated from its octanol/water, $\mathrm{K}_{\mathrm{ow}}$, and air/water, $\mathrm{K}_{\mathrm{aw}}$, partition coefficients. Weschler and Nazaroff (2010) have calculated $\mathrm{K}_{\mathrm{oa}}$ values for phthalate esters at $25{ }^{\circ} \mathrm{C}$ using the SPARC online calculator. Those values are listed in Table 5 and used in the present study. An estimation of $1 \times 10^{6} \mathrm{~g} / \mathrm{m}^{3}$ is employed as the density of airborne particles (Turpin and Lim 2001).

\section{Partitioning between gas Phase AND Settled duSt}

A detailed description of SVOC partitioning between the gas phase and settled dust indoors is given by Weschler and Nazaroff (2010). An equilibrium coefficient, $\mathrm{K}_{\mathrm{dg}}$ $\left(\mathrm{m}^{3} / \mu \mathrm{g}\right.$ dust) was defined to describe an SVOC's partitioning between settled dust and gas phase:

$$
K_{d g}=\frac{X_{d u s t}}{y_{0, s u r f}}
$$

For equilibrium conditions, the partition coefficient $\mathrm{K}_{\mathrm{dg}}\left(\mathrm{m}^{3} / \mu \mathrm{g}\right.$ dust) can be estimated by:

$K_{d g}=\frac{f_{o m_{-} d u s t} \times K_{o a}}{\rho_{\text {dust }}}$

where $\mathrm{f}_{\text {om_dust }}$ is the fraction of settled dust that is organic matter and $\rho_{\text {dust }}\left(\mu \mathrm{g} \mathrm{dust} / \mathrm{m}^{3}\right)$ is the dust density. An indoor dust density of $2 \times 10^{6} \mathrm{~g} / \mathrm{m}^{3}$ is assumed, which is reported by field measurements and consistent with typical dust composition (Hunt et al. 1992; Morawska and Salthammer 2003; Weschler and Nazaroff 2010). 


\section{SURFACE ADSORPTION}

For a strongly sorbing SVOC, interior surfaces may perform as a significant sorptive reservoir and thus play an important role in the fate and transport of the compound. As shown in Illustration 2, assuming a linear equilibrium relationship for phthalates, the ratio of the concentration of a chemical on a surface to its concentration in the gas phase is equal to the surface/air partition coefficient, $\mathrm{K}_{\text {surf }}(\mathrm{m})$, or

$K_{\text {surf }}=C_{\text {surf }} / y_{0, \text { surf }}$

where $\mathrm{C}_{\text {surf }}\left(\mu \mathrm{g} / \mathrm{m}^{2}\right)$ is the phthalate concentration on surface and $\mathrm{y}_{0, \text { surf }}\left(\mu \mathrm{g} / \mathrm{m}^{3}\right)$ is the gas phase concentration immediately adjacent to the surface. Without the presence of dust on the surface, the amount of phthalate accumulated on the surface will be equal to the total mass transferred through the boundary layer from the gas phase. However, particle deposition complicates the problem. When the sorbing particles deposit on a sink surface, they will release the adsorbate to the gas layer adjacent to the surface and thus enhance mass transfer. The amount that the adsorbate can be released is governed by the concentration difference between $\mathrm{y}_{0}$, surf and $\mathrm{y}$. The compound that is released will be redistributed between the surface, dust loaded on the surface, and gas layer adjacent to the surface. Resuspension will make the sorbing particles perform as a secondary source transporting the compound back to the bulk air. Therefore, the amount of phthalate accumulated on the surface and settled dust is expressed as:

$$
\begin{aligned}
A_{i} \frac{d C_{\text {surf }_{j}}}{d t}+ & M_{k} \cdot A_{k} \frac{d X_{d u s t, k}}{d t}+A_{k} \cdot \delta_{k} \cdot \frac{d y_{0, \text { surf }_{k}}}{d t} \\
= & h_{m, k}\left(y-y_{0, \text { surf }_{i}}\right) A_{k}+\overline{v_{d k}} \cdot A_{k} \cdot F_{k}-R_{k} \cdot X_{d u s t, k} \\
& \cdot M_{k} \cdot A_{k}
\end{aligned}
$$


where $M_{k}$ represents the total settled dust on the surface at time t, which can be calculated by Equation 2 as mentioned previously. $\frac{d X_{d u s t, k}}{d t}$ is the DEHP mass-fraction change per unit time and $\delta_{k}(\mathrm{~m})$ is the thickness of the organic film layer immediately adjacent to the $\mathrm{k}^{\text {th }}$ surface. In Equation (12), the last term on the right side represents the amount of DEHP comes of the surface through resuspension. In our model, resuspension is assumed to occur on floor surfaces (i.e., vinyl flooring, carpet surface and wood floor), and thus the resuspension rate, $R_{k}$, is set to zero for other surfaces. Equation (11) and (12) are assumed to apply to phthalate transferring between bulk air and all exposed nonporous surfaces, such as furniture, glass window, ceiling and wall. The thickness of the organic film is about $10-100 \mathrm{~nm}$, which is considerably small (Bennett and Furtaw 2004). Therefore, we ignored the mass change in the organic film layer above a given surface, which is the third term on the left side of Equation 12.

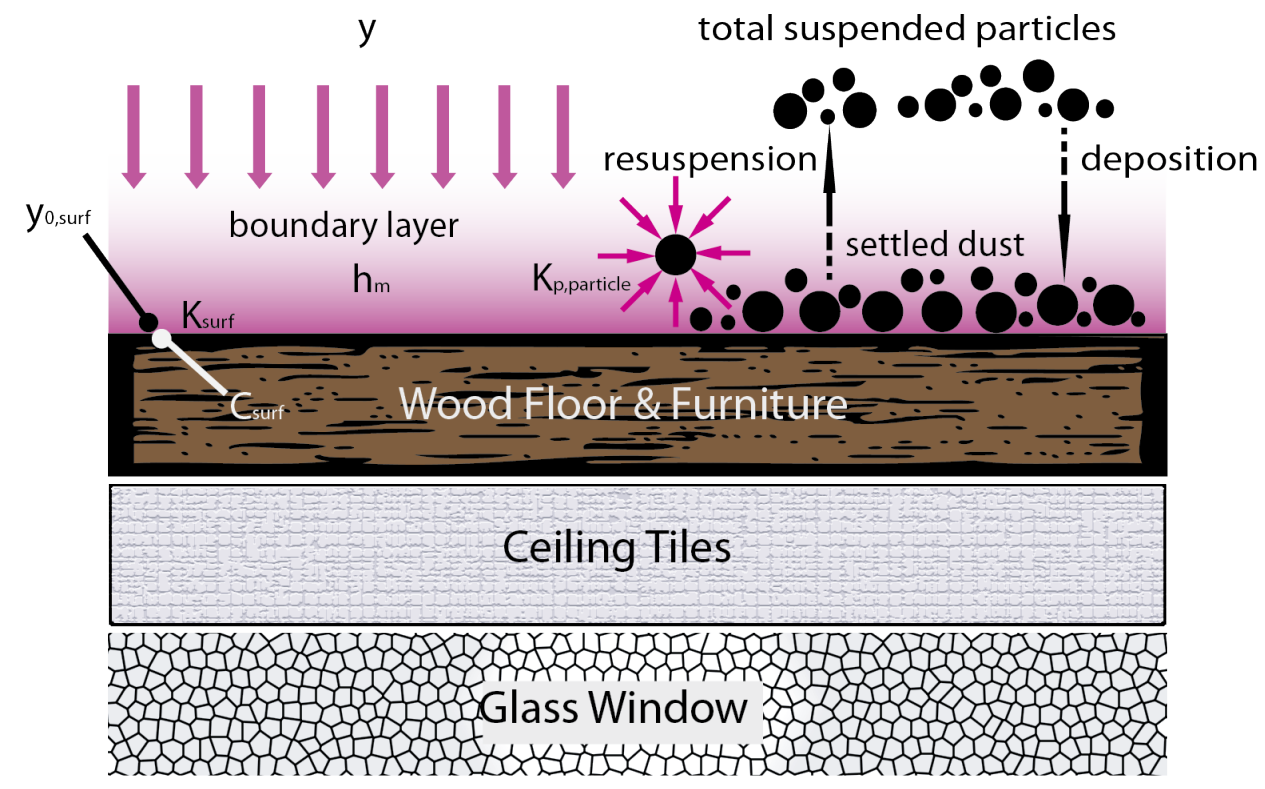

Illustration 2: Schematic of sorption process for nonporous surface. Note that the three individual materials shown for illustrative purposes and do not comprise a layered structure. 


\section{MASS TRANSFER COEFFICIENT}

The mass transfer coefficient for boundary layer adjacent to an interior surface, $h_{m, k}$, was estimated in this model using correlation equations (Alexy 1991). The equations express the mass transfer coefficient as a function of Reynolds number and Schmidt number. In order to solve for mass transfer coefficients across various interior surfaces, we employed measurement results of indoor air velocities in a typical house in the United States (Huang et al. 2004). It was found that the indoor air velocities were within the range of $0.01-0.16 \mathrm{~m} / \mathrm{s}$ and the values near interior surfaces were higher than those at the center of the house. In this study, the measured near-surface velocities were used to calculate the mass transfer coefficients for each interior surface.

\section{SURFACE ABSORPTION}

Porous surface may be important phthalate sinks because of their large effective surface area. With millions of fibers per square meter woven tightly into a textile backing, carpet may, therefore, be a significant reservoir for both SVOCs compounds and settled dust. As shown in Illustration 3, phthalates are transferred from indoor air into carpet in gas and physically adsorbed phases. The approach used is consistent with that developed previously for sorption of VOCs to porous building materials (Haghighat et al. 2005; Xiong et al. 2008; Deng et al. 2009). The governing equation describing transient diffusion through carpet pores and sorption onto carpet fibers and settled dust is:

$\left[\varepsilon+(1-\varepsilon) K_{s}+K_{p g} \cdot \frac{M_{c a}}{L}\right] \frac{\partial C_{g}}{\partial t}=\left[\varepsilon \cdot D_{i a}+(1-\varepsilon) D_{s} \cdot K_{s}\right] \frac{\partial^{2} C_{g}}{\partial x^{2}}$

where $\varepsilon$ is the porosity of carpet, $K_{S}$ is the gas/fiber partition coefficient of phthalate, $\mathbf{M}_{\text {ca }}$ $\left(\mu \mathrm{g}\right.$ particle $\left./ \mathrm{m}^{3}\right)$ is the average dust concentration in the carpet. $C_{g}\left(\mu \mathrm{g} / \mathrm{m}^{3}\right)$ is the gas- 
phase phthalate concentration in the carpet as a function of time and depth of the carpet. $D_{s}\left(\mathrm{~m}^{2} / \mathrm{h}\right)$ is the diffusion coefficient of phthalates within the carpet fibers and $D_{i a}\left(\mathrm{~m}^{2} / \mathrm{h}\right)$ is the diffusion coefficient of phthalates in air. Because diffusion coefficient in solid is five orders of magnitude less than in air and thus insignificant, we use $D_{s} \sim 1 \times 10^{-10} \mathrm{~m}^{2} / \mathrm{h}$ as a representative value, based on $\mathrm{C}_{12}-\mathrm{C}_{15}$ alkanes in vinyl flooring (Cox et al., 2001). The values of other properties are listed in Table 4 .

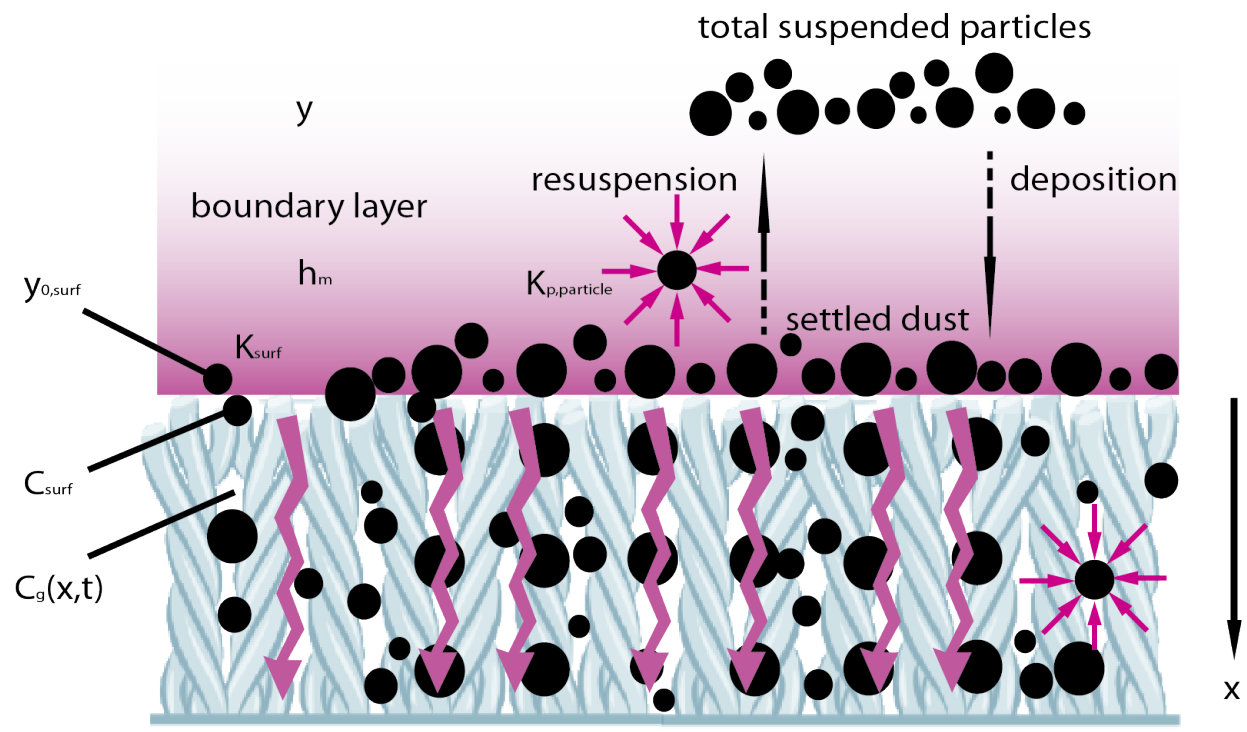

Illustration 3: Schematic of absorption process of carpet.

The initial condition assumes that no phthalates present in the carpet, or

$\left.C_{g}(x, t)\right|_{t=0}=0$

Given the impermeable condition at the bottom of the carpet, the lower boundary condition is:

$-\left.D_{i a} \frac{\partial C_{g}}{\partial x}\right|_{x=L}=0$ 
where $\mathrm{L}(\mathrm{m})$ is the thickness of the carpet. The second boundary condition imposed at the upper surface is:

$\left.C_{g}\right|_{x=0}=y_{0, \operatorname{surf}_{c a}}$

Although the surface dust loading on carpet $\left(\mu \mathrm{g} / \mathrm{m}^{2}\right)$ can be calculated based on Equation 1 and Equation 2, the concentration of settled dust within the carpet is hard to estimate. Therefore, we assume the settled dust is uniformly distributed in the carpet as a function of depth.

\begin{tabular}{lll}
\hline Property name (units) & symbol & mean value \\
\hline carpet thickness $(\mathrm{m})$ & $\mathrm{L}$ & $1.0 \times 10^{-2}$ \\
partition coefficient (unitless) & $\mathrm{K}_{\mathrm{s}}$ & $1.7 \times 10^{5}$ \\
diffusion coefficient in air $\left(\mathrm{m}^{2} / \mathrm{h}\right)$ & $\mathrm{D}_{\mathrm{ia}}$ & $1.15 \times 10^{-2}$ \\
diffusion coefficient in fiber $\left(\mathrm{m}^{2} / \mathrm{h}\right)$ & $\mathrm{D}_{\mathrm{s}}$ & - \\
surface area $\left(\mathrm{m}^{2}\right)$ & $\mathrm{A}_{\mathrm{ca}}$ & 35.8 \\
porosity (unitless) & $\varepsilon$ & 0.9 \\
\hline
\end{tabular}

Table 4: $\quad$ Properties for carpet absorption of DEHP.

In addition to DEHP, three other phthalates, DMP, BBP and DIDP are included to compare to DEHP. In Table 5, the surface/air partition coefficients of phthalates are calculated based on the linear correlations between partition coefficients and vapor pressure of the compound (Xu et al. 2009). The vapor pressure of each phthalate is calculated by using US EPA's Estimation Programs Interface (EPI) suite. Although compound with higher molecular weight should have less volatility, the vapor pressure of DiDP is higher than that of DEHP, which might be due to the difficulties of measuring the vapor pressure of semi-volatile compounds. However, no contradiction was observed for $\mathrm{K}_{\mathrm{oa}}$ values, which increase with molecular weight increase. 


\begin{tabular}{lrrrr}
\hline SVOCs & DMP & BBP & DEHP & DIDP \\
\hline Case No. & $131-11-3$ & $85-68-7$ & $117-81-7$ & $26761-40-0$ \\
Molecular weight $/(\mathrm{g} / \mathrm{mol})$ & 194.18 & 312.37 & 390.56 & 446.74 \\
Vapor pressure $/ \mathrm{mmHg}^{1}$ & $3.80 \mathrm{E}-03$ & $5.03 \mathrm{E}-05$ & $1.43 \mathrm{E}-07$ & $5.28 \mathrm{E}-07$ \\
$\mathrm{~K}_{\text {oa }^{2}}$ & $4.90 \mathrm{E}+06$ & $1.04 \mathrm{E}+09$ & $7.94 \mathrm{E}+12$ & $5.05 \mathrm{E}+14$ \\
Ceiling and wall $/ \mathrm{m}_{\text {Carpet } / \mathrm{m}}$ & 0.90 & 26.21 & 2523.44 & 912.15 \\
Wood floor $/ \mathrm{m}$ & 2.74 & 41.22 & 1627.81 & 717.64 \\
Furniture $/ \mathrm{m}$ & 0.90 & 26.21 & 2523.44 & 912.15 \\
Window $/ \mathrm{m}$ & 0.90 & 26.21 & 2523.44 & 912.15 \\
Tile $/ \mathrm{m}$ & 1.36 & 39.47 & 3800.00 & 1373.59 \\
\hline
\end{tabular}

Table 5: $\quad$ Physical and sorption properties of phthalates

\footnotetext{
${ }^{1}$ The vapor pressure values in this row are calculated by Estimation Programs Interface (EPI) Suite released by US EPA.

${ }^{2} \mathrm{~K}_{\text {oa }}$ definition: octonal-air partition coefficient, determined using SPARC online calculator release w4.5 (September 2009) done by Weschler and Nazaroff (2010).
} 


\section{Chapter 3: Results and Discussion}

\section{Particle And Dust loading}

The baseline parameters used in modeling are listed in Table 4 and Table 5. The simulation process lasted for 1200 days, which we believed to be sufficient to understand the indoor environmental fate of the SVOCs based on previous studies. Experimental results from CLIMPAQs by Clausen et al. (2004) showed the gas phase concentrations in chambers increased slowly and reached steady state after 150 days. Xu et al. (2009) calculated the gas phase and adsorbed surface DEHP in a two-room model for 1000 days and showed that gas phase DEHP in one room reached steady state within a year while in the adjacent room the gas phase reached steady state after three months. The outdoor particle concentrations are listed in Table 2 and we assume the concentrations to be constant over the calculation period.

Figure 1 shows the simulation results of total suspended particle (TSP) concentration in the residential house based on the outdoor particle level in Houston, TX. Given the fact that particle penetration rates for particles with different size fractions through building envelope are less than one (Table 2), it is reasonable that the indoor TSP concentration in each compartment is less than the outdoor TSP concentration, especially for particles with size larger than $100 \mu \mathrm{m}$ (Riley et al. 2002). Because the indoor particle sources are not included in baseline condition, the average TSP concentration in each compartment is less than the typical indoor value of $20 \mu \mathrm{g} / \mathrm{m}^{3}$ (Polidori et al. 2006; Weschler and Nazaroff 2008). The indoor TSP level is thus controlled by air exchange rate, because the outdoor TSP is assumed constant and is the only source for baseline case. Therefore, bathroom has the lowest TSP concentration compared to kitchen and main house due to its low air exchange rate with outside. 


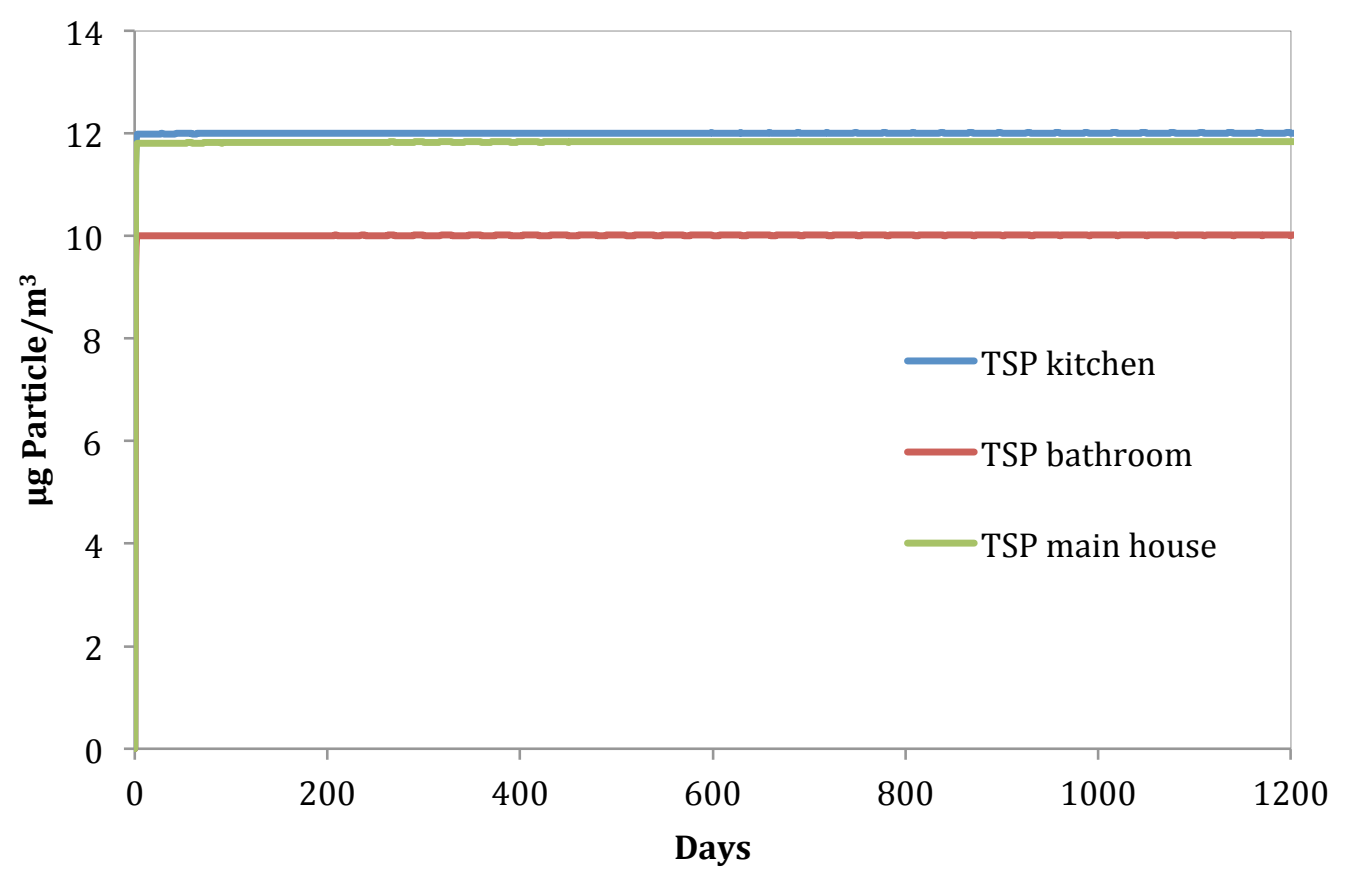

Figure 1: TSP concentrations in each compartment.

In a realistic residential house, suspended particles can deposit and keep accumulating on interior surfaces, as denoted by dust loading. Dust loading on a surface is determined by TSP concentration, deposition velocities for particles and domestic activities such as cleaning. Figure 2 shows the dust loading on different interior surfaces in the main house. As expected, because the deposition velocity for particles onto the floor is larger than that onto horizontal surfaces or upward surfaces, floors have much higher dust loading than other surfaces like ceiling and wall. In the model, we also included cleaning as a domestic activity that happens at times. The cleaning frequency is set to be once a month and the efficiency for interior surfaces is $60 \%$ each time except for carpet, which is only $10 \%$ because of the difficulty of removing settled dust from carpets 
(Yiin et al. 2002). Hence, carpet has a higher dust loading than wood floor (Figure 2). In addition, Bennett and Furtaw (2004) provided typical indoor dust loading on carpet $\left(1.0 \times 10^{7} \mu \mathrm{g} / \mathrm{m}^{2}\right)$ and hard floor $\left(8.5 \times 10^{4} \mu \mathrm{g} / \mathrm{m}^{2}\right)$. Our model predictions are close to their values. The small discrepancy may due to the lower TSP concentrations caused by the absence of indoor particle sources.

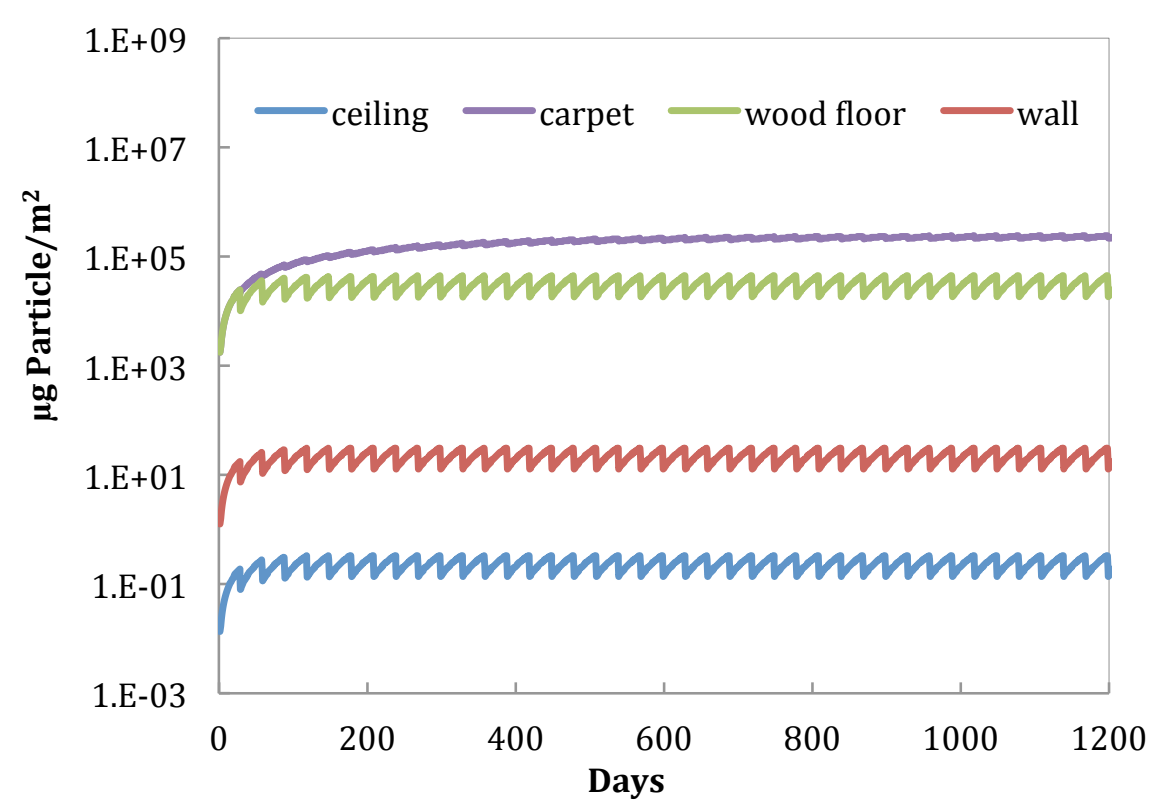

Figure 2: Dust loading in the main house. 


\section{GAS PHASE AND AIRBORNE DEHP CONCENTRATION}

In this study, both gas-phase concentration and total airborne concentration of DEHP are calculated. Total airborne concentration of DEHP is the sum of the pure gasphase in bulk air and the amount adsorbed onto suspended particles. It is the concentration reported by most field studies and important to human inhalation exposure. Figure 3 shows the gas phase DEHP concentration in each compartment. The steep initial rise of DEHP concentration is mainly due to the existence of boundary layer above each sorption surface. It results that the DEHP emitted from vinyl flooring is not able to be taken up instantly by the sink surfaces because of the relatively slow gas diffusion through the stagnant air layer. In Figure 3, the main house had the lowest DEHP concentration when compared with the other two compartments because the main house has the larger ratio of sorption area (e.g. walls, furniture) to emission surface area (vinyl flooring). Figure 4 shows the predicted airborne DEHP concentrations in each compartment. Compared to field measurements in homes and daycare centers in US and Europe (Table 6), the predicted concentrations in this study are within the similar range. As shown in Table 6, the airborne DEHP concentration is nearly two orders of magnitude greater than the pure gas phase concentration, which agree very well with the model prediction. The result implies that the airborne DEHP is mainly present in suspended particles as particle-bound DEHP and only a small amount is present in gas phase due to the strong partition effect between the gas phase and suspended particles. Both the gas phase and airborne DEHP are subject to minor fluctuations (Figure 3 and 4) because of the monthly clean activity. Periodically removal of settled dust from various interior surfaces will result the change of the resuspended particles and finally influence DEHP in bulk air. 


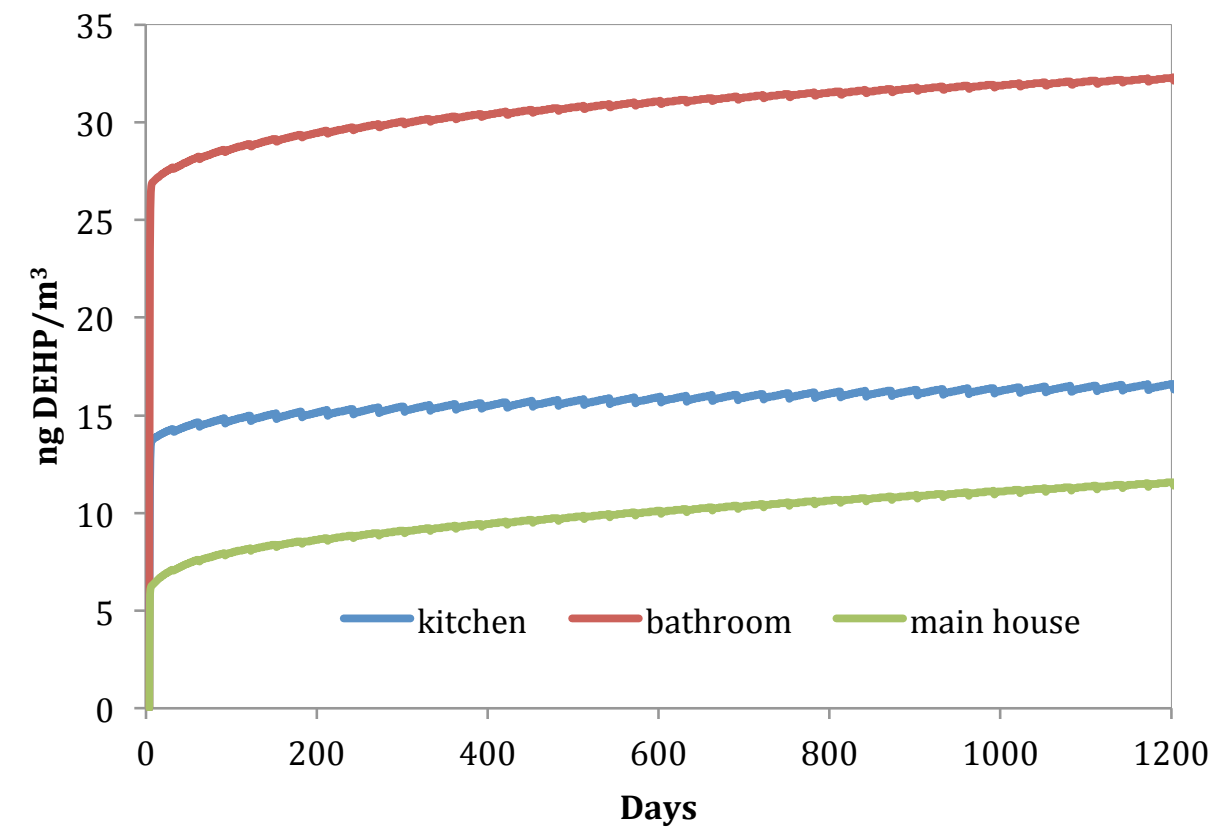

Figure 3: The gas phase DEHP concentrations in each compartment.

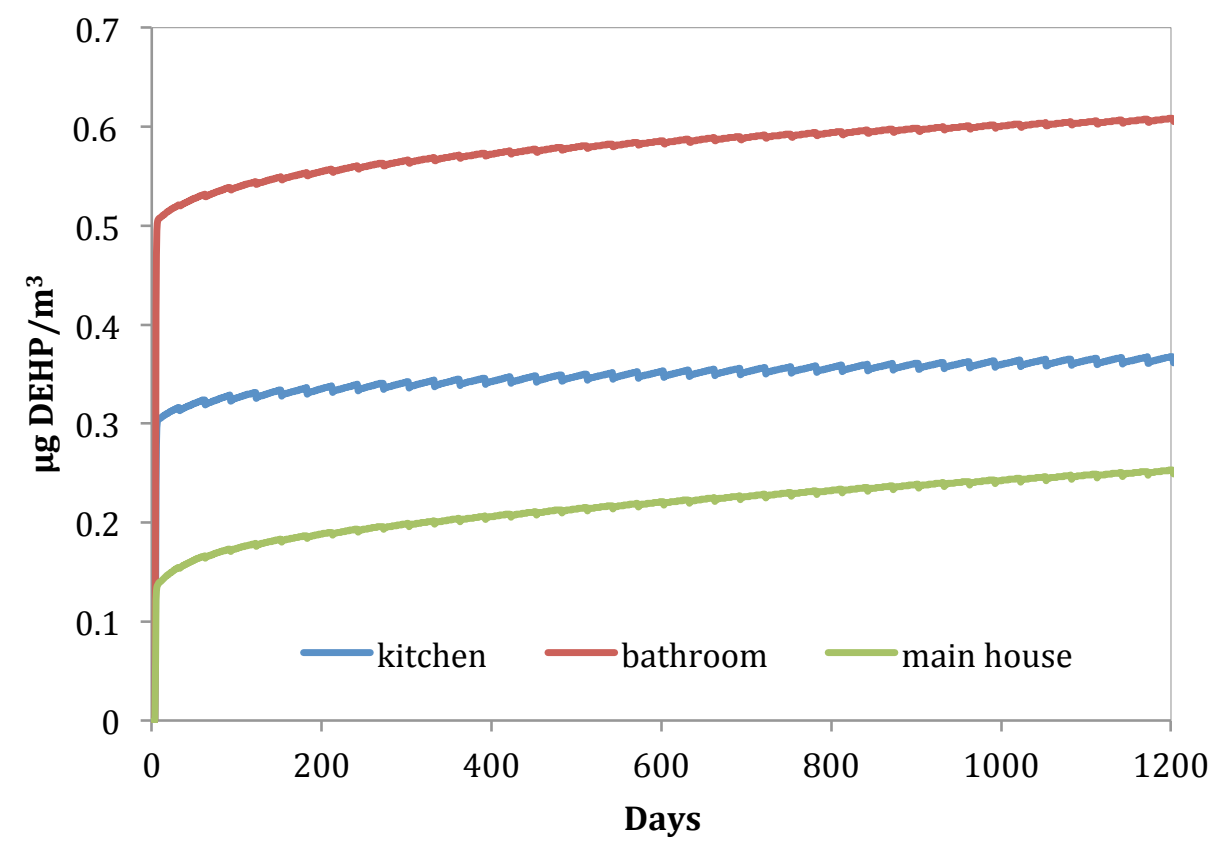

Figure 4: The airborne DEHP concentrations in each compartment. 


\begin{tabular}{|c|c|c|c|c|c|c|}
\hline $\begin{array}{l}\text { DEHP } \\
\text { gas pha }\end{array}$ & e concentration $\left(\mu \mathrm{g} / \mathrm{m}^{3}\right)$ & $\begin{array}{l}\text { inferred gas } \\
\text { phase }\left(\mathrm{ng} / \mathrm{m}^{3}\right)\end{array}$ & $\begin{array}{l}\text { airborne } \\
\left(\mathrm{ng} / \mathrm{m}^{3}\right)\end{array}$ & $\begin{array}{l}\text { present } \\
\text { gas phase } \\
5-10\end{array}$ & $\begin{array}{l}\text { present } \\
\text { airborne } \\
100-500\end{array}$ & reference \\
\hline & $\begin{array}{l}30 \text { apartments, Berlin, } \\
\text { DE }\end{array}$ & 2 & 128 & & & $\begin{array}{l}\text { Fromme et al. } 2004 \\
\text { Weschler et al. } 2008\end{array}$ \\
\hline & $\begin{array}{l}41 \text { houses, Sapporo, } \\
\text { JPN }\end{array}$ & 2.3 & 147 & & & $\begin{array}{l}\text { Kanazawa et al. } \\
2010\end{array}$ \\
\hline & $\begin{array}{l}120 \text { houses, Cape Cod, } \\
\text { Massachusetts, USA }\end{array}$ & 1.2 & 77 & & & Rudel et al. 2003 \\
\hline
\end{tabular}

Table 6: $\quad$ Predicted indoor air DEHP concentration compared with those cited in literature.

\section{DEHP ON INTERIOR SURFACES}

We examined the DEHP concentrations on interior surface in each compartment over 1200 days, as shown in Figure 5 and 6. The predicted DEHP on window and tile surfaces are 2 times higher than on the other surfaces due to the high window (tile)/air partition coefficient. The surface/air partition coefficients (Table 5) were estimated by linear regression results for several SVOCs in a previous study (Xu et al. 2009). The DEHP on a given surface consists of the surface phase and dust phase, of which the surface DEHP is controlled by surface/air partitioning while the dust-bounded DEHP is mainly dependent on dust loading and dust/air partitioning. For horizontally-oriented surfaces (e.g. wall, window) and upward vertically-oriented surfaces (e.g. ceiling), the amount of settled dust is at low level (Figure 2), hence the surface adsorbed DEHP contributes a great portion to the total DEHP on the surface. In contrast, downward vertically-oriented surfaces (e.g. carpet and wood floor) have considerably higher level of settled dust compared to other surfaces (Figure 2), therefore the total DEHP on carpet and wood floor consists mostly of dust-bounded DEHP. This explains why in Figure 6 the DEHP on carpet and wood floor is orders of magnitude higher than that on other surfaces such as ceiling and wall, though the surface/air DEHP partition coefficients for all interior surfaces in this model are ranging from 1700 to $3800 \mathrm{~m}$ (Table 5). 


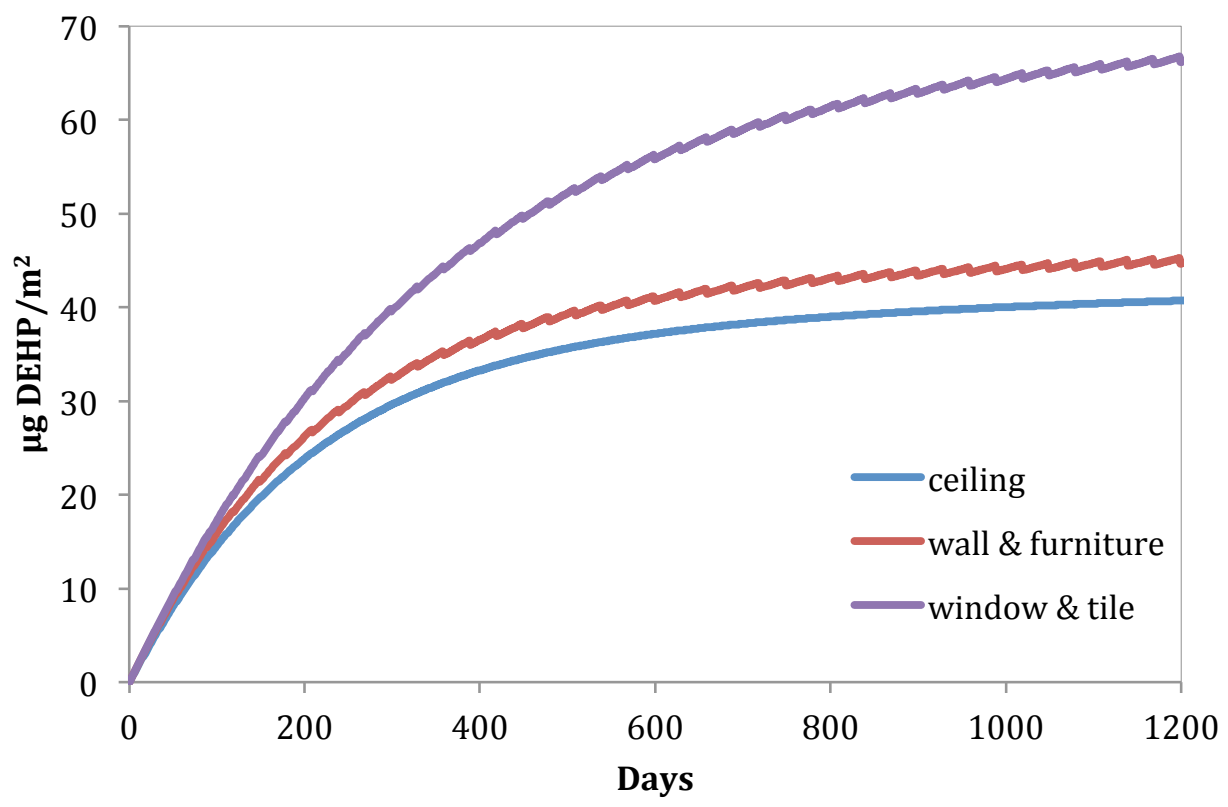

Figure 5: Surface DEHP concentrations in the kitchen.

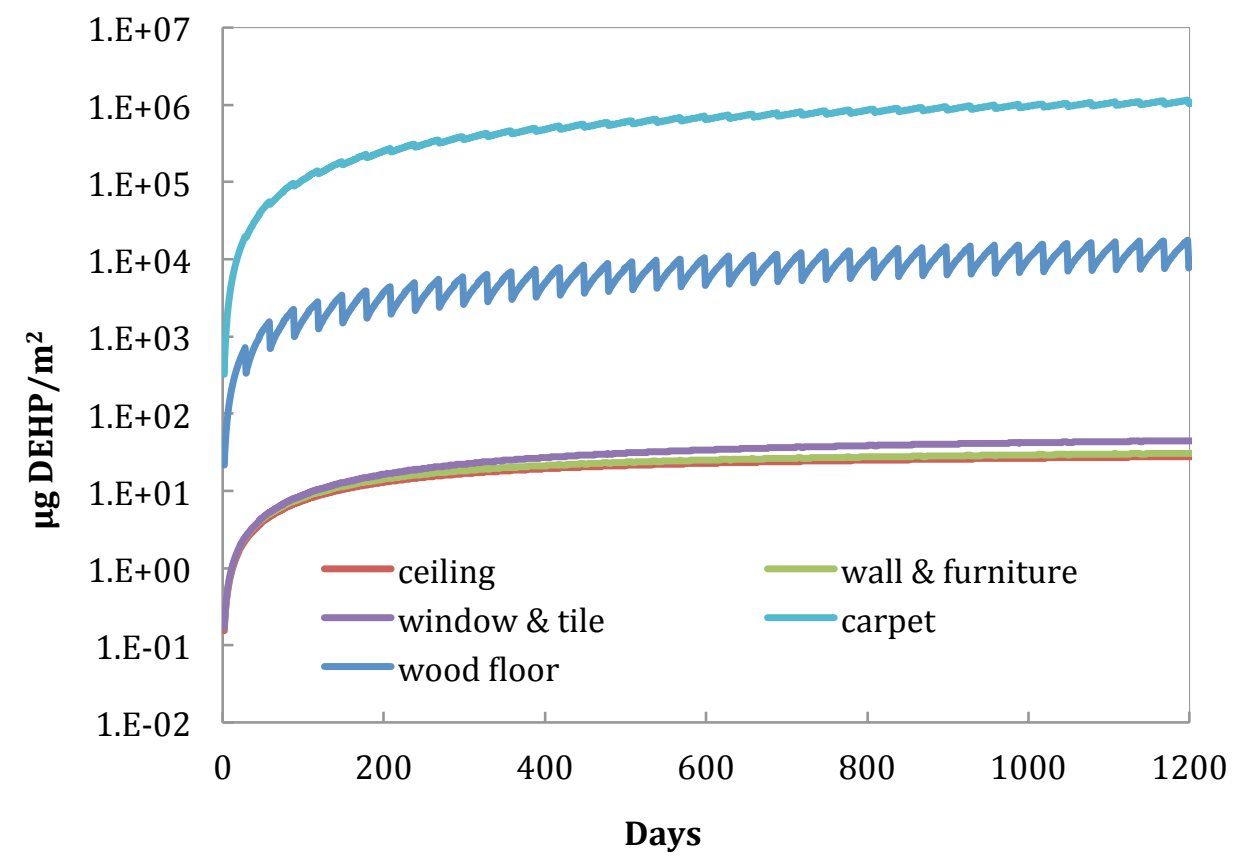

Figure 6: DEHP concentration on interior surfaces in the main house. 


\section{DEHP MASS-FRACTION IN SETTLED DUST}

Figure 7 shows the model-predicted mass fraction of DEHP in settled dust on wall surface (the results of other surfaces show similar curves, so only the values for wall surface are presented here). It was then compared with the measurements in chamber and field studies. As discussed in Equation 9 and 10, DEHP mass-fraction in settled dust is calculated based on gas phase concentration in the boundary layer adjacent to a given surface. Compared with the values from field studies, which were ranging from 2000$16000 \mu \mathrm{g} \mathrm{DEHP} / \mathrm{g}$ dust, the predicted results within 400 days are reasonable.

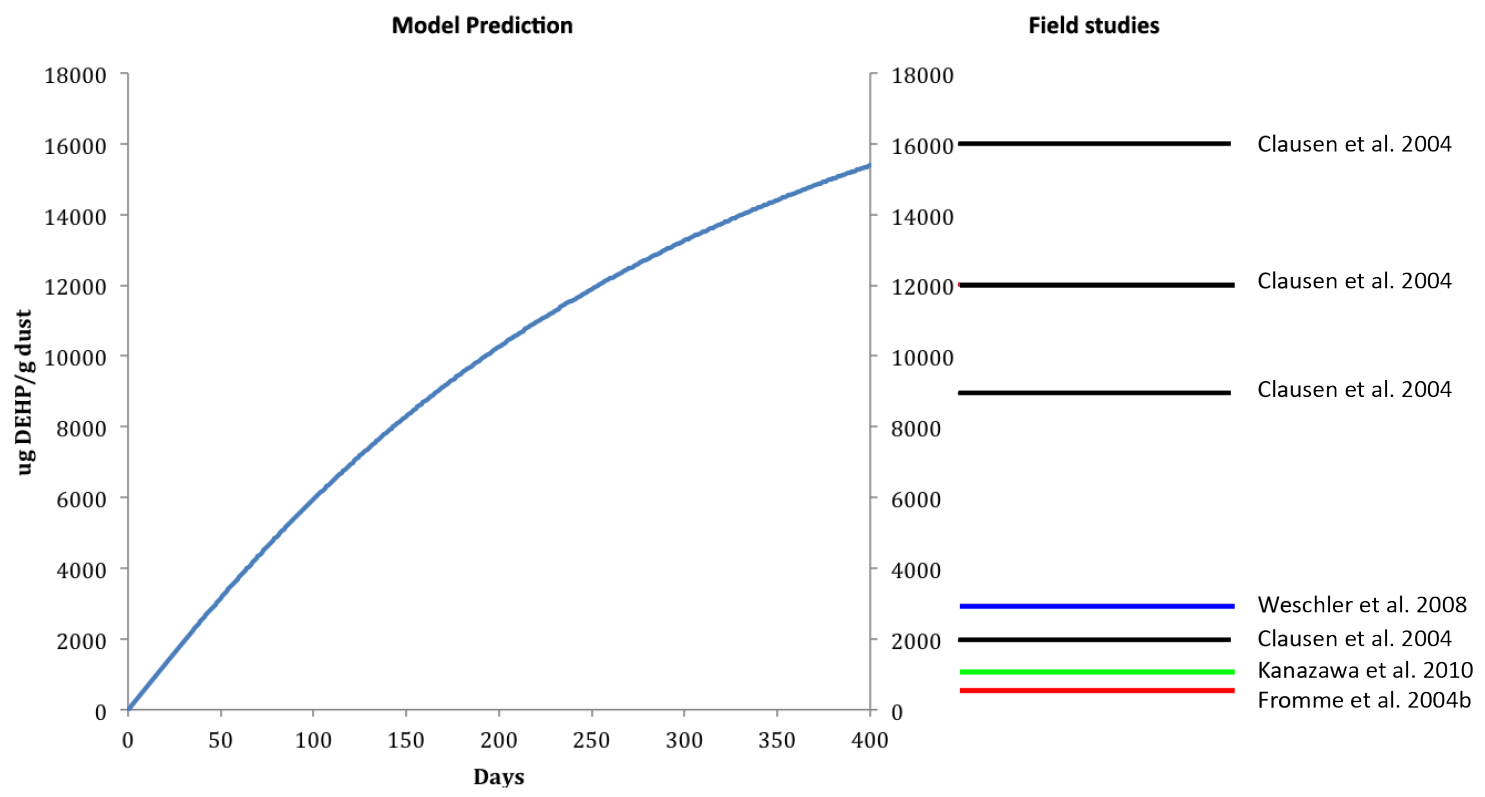

Figure 7: $\quad$ Predicted mass-fraction in settled dust on the wall and field studies.

\section{IMPACT OF AIR EXCHANGE RATE}

Figure $8-12$ show the impact of air exchange rate on the indoor TSP concentration, gas phase DEHP concentration and surface DEHP concentration in the main house (the calculation results give similar curves so only main house results are presented). Increasing air exchange rate will increase indoor TSP level by ventilating 
more outdoor particles (Figure 8) and gas phase DEHP emission rate from the vinyl flooring while the increased indoor TSP concentration will result in a substantial reduce in the gas phase DEHP concentration (Figure 9) as more DEHP will adsorb to the suspended particles. With higher air exchange rate, the emission rate of DEHP from vinyl flooring increased because the mass concentration gradient in the boundary layer above a given surface would increase as the gas phase DEHP concentration was reduced, simultaneously, the mass transfer coefficients were also increased due to the higher velocity above the surfaces.

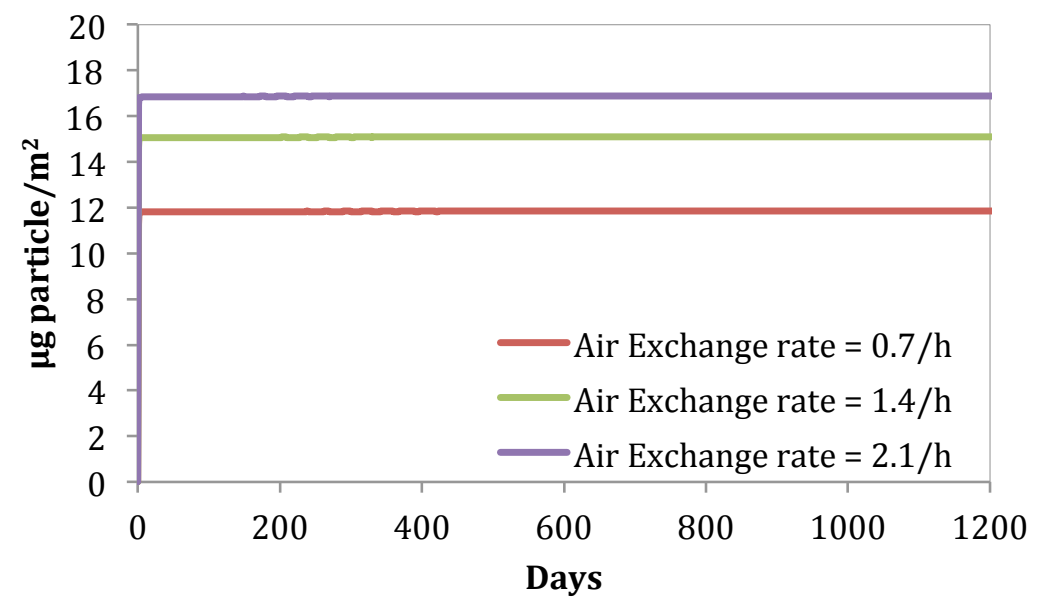

Figure 8: Indoor TSP concentrations under different air exchange rates in the main house.

As shown in Figure 10, the increase in air exchange rate also resulted in a decrease in airborne DEHP concentration in the main house though the change is smaller than pure gas phase (Figure 9) due to the compromise of a higher indoor TSP concentration. Similarly, as shown in Figure 11, the DEHP on horizontally- and upward vertically-oriented interior surfaces decreased with increasing the air exchange rate because DEHP on these surfaces consists mostly of surface adsorbed DEHP rather than 
dust-bounded DEHP and the surface adsorbed DEHP was reduced due to the decreased gas phase DEHP. However, carpet and wood floor, both of which are downward vertically-oriented surfaces, the DEHP on the surface increased with higher air exchange rate (Figure 11) because the DEHP in settled dust accounts for the majority of total DEHP on these surfaces and therefore the larger dust loading due to the higher TSP level resulted in more DEHP on carpet and wood floor.

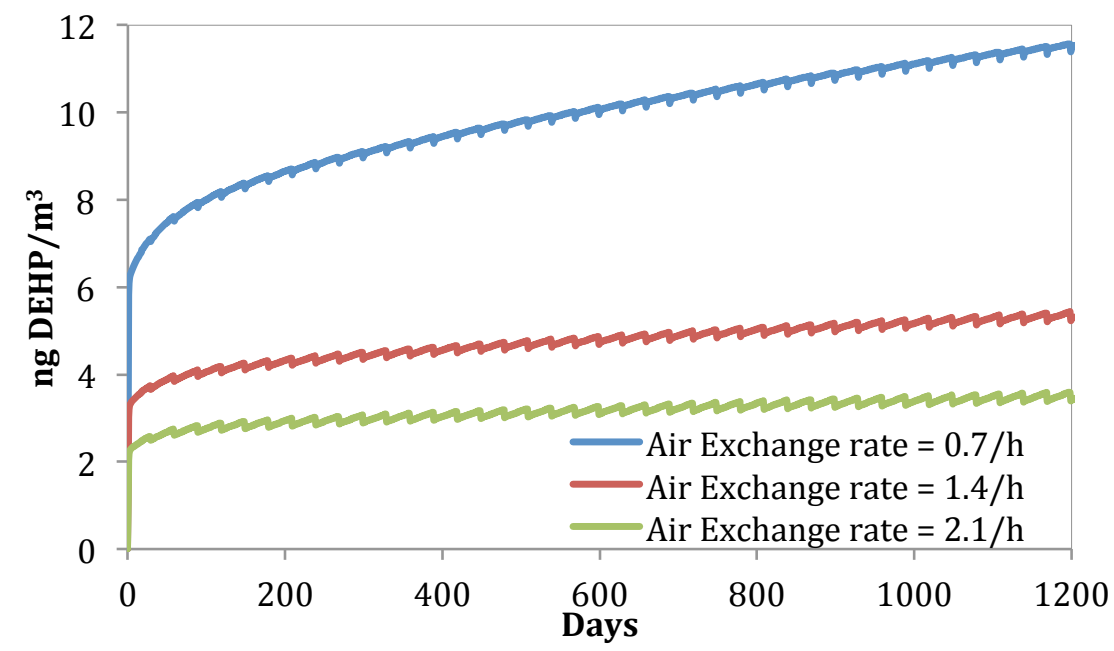

Figure 9: Impact of air exchange rate on the gas phase DEHP in the main house.

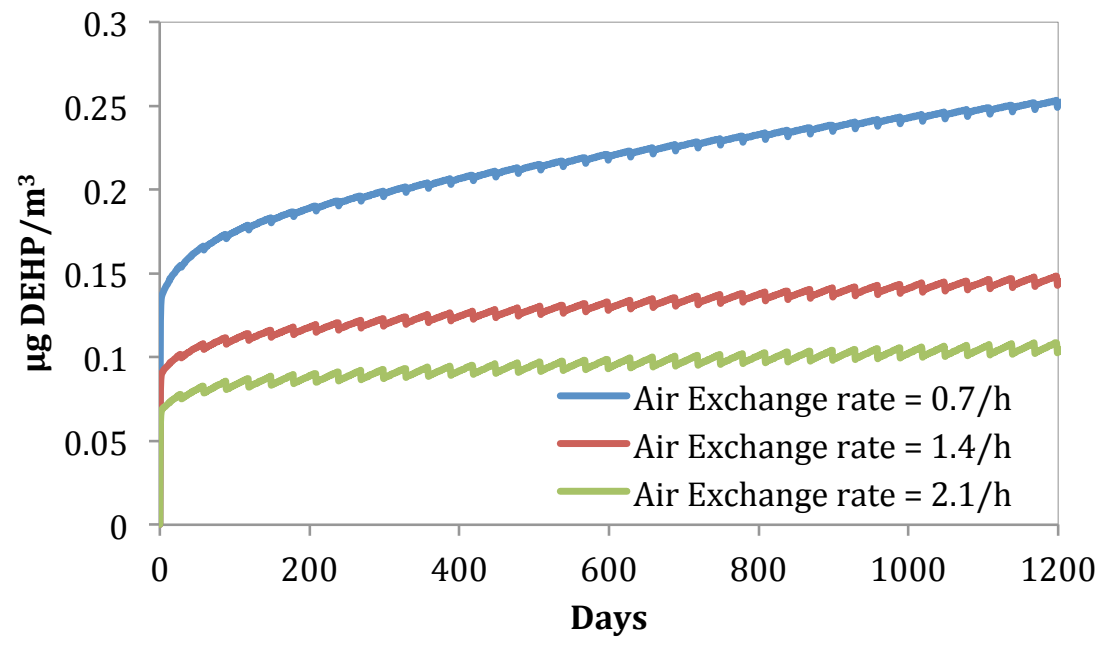

Figure 10: Impact of air exchange rate on the airborne DEHP in the main house. 


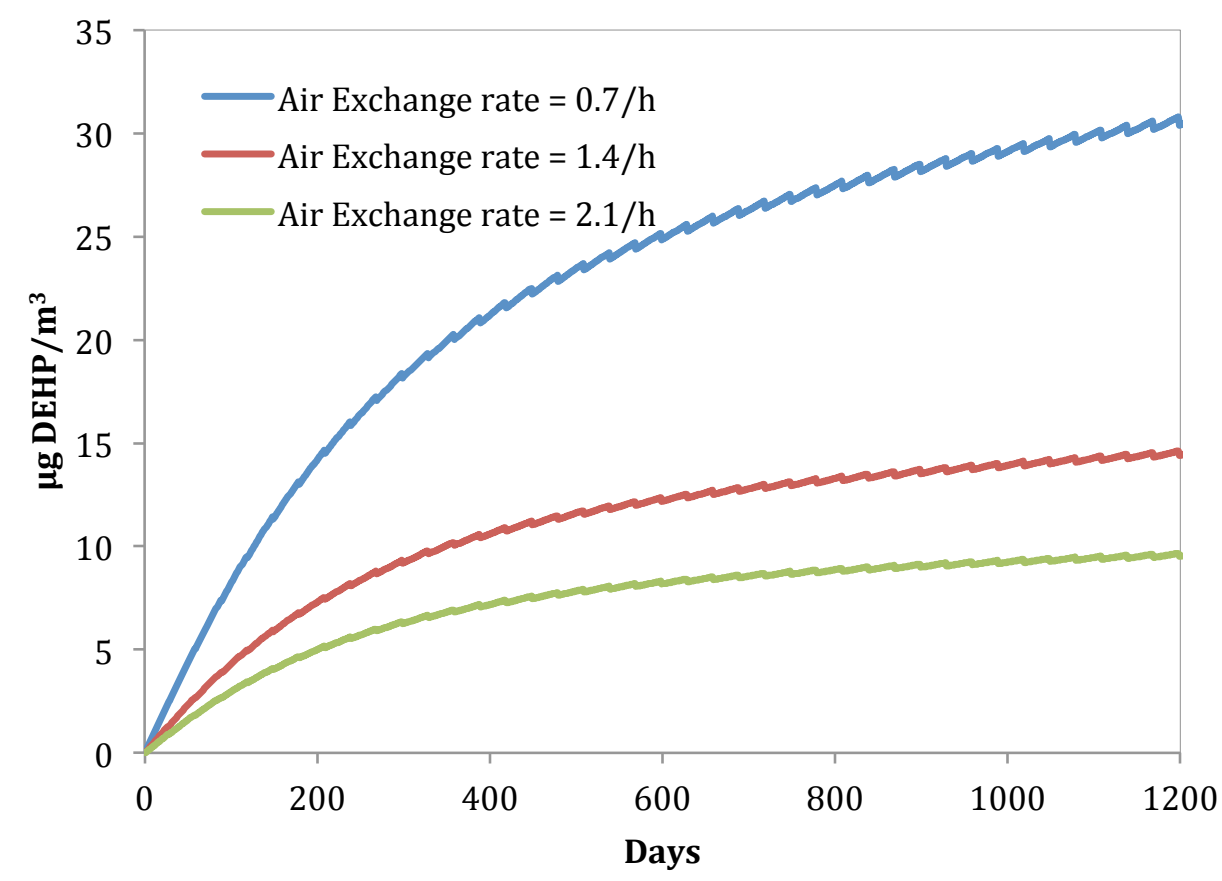

Figure 11: Impact of air exchange rate on DEHP on wall surface in the main house.

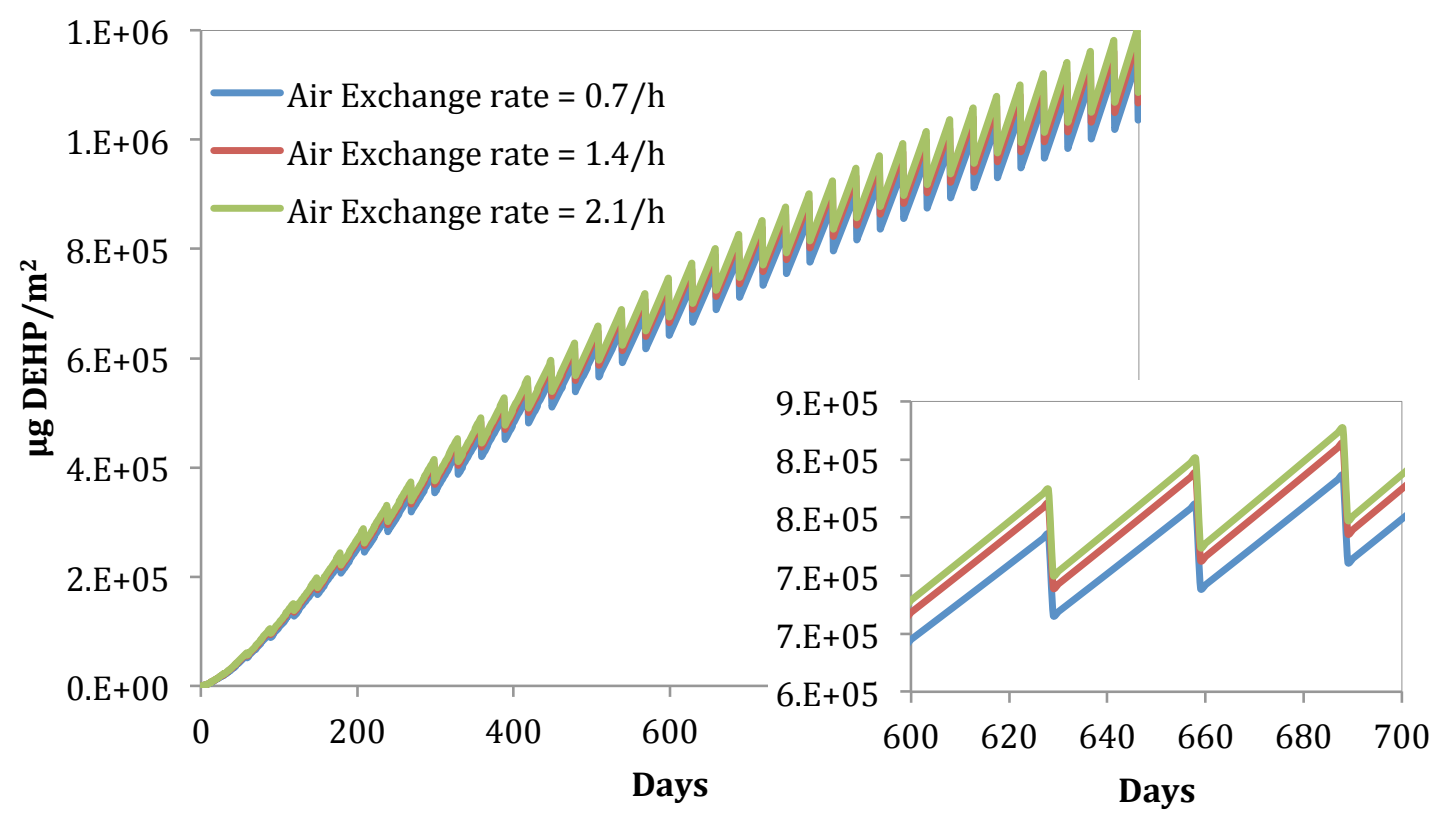

Figure 12: Impact of air exchange rate on DEHP on carpet in the main house. 


\section{IMPACT OF SUSPENDED PARTICLES}

As listed in Table 2, the outdoor particle concentration in Beijing is considerably higher than that in Houston, which resulted that the indoor TSP level in Beijing is also much higher than that in Houston with other conditions unchanged (Figure 13). Higher indoor TSP level will result in lower gas phase DEHP concentration because most of the airborne DEHP is adsorbed on suspended particles as discussed previously. Hence, the gas phase DEHP presents at a much lower level in Beijing compared to the results in Houston (Figure 14). In addition, the indoor gas phase DEHP concentration of Beijing oscillates more severely than the curve of Houston, and we believe it is due to the monthly cleaning activities removing more dust from interior surfaces located in Beijing. Since the cleaning efficiencies are the same for both cases, the amount of resuspended particles will decrease more after cleaning in Beijing than in Houston, which enlarged the difference of gas phase DEHP before and after cleaning.

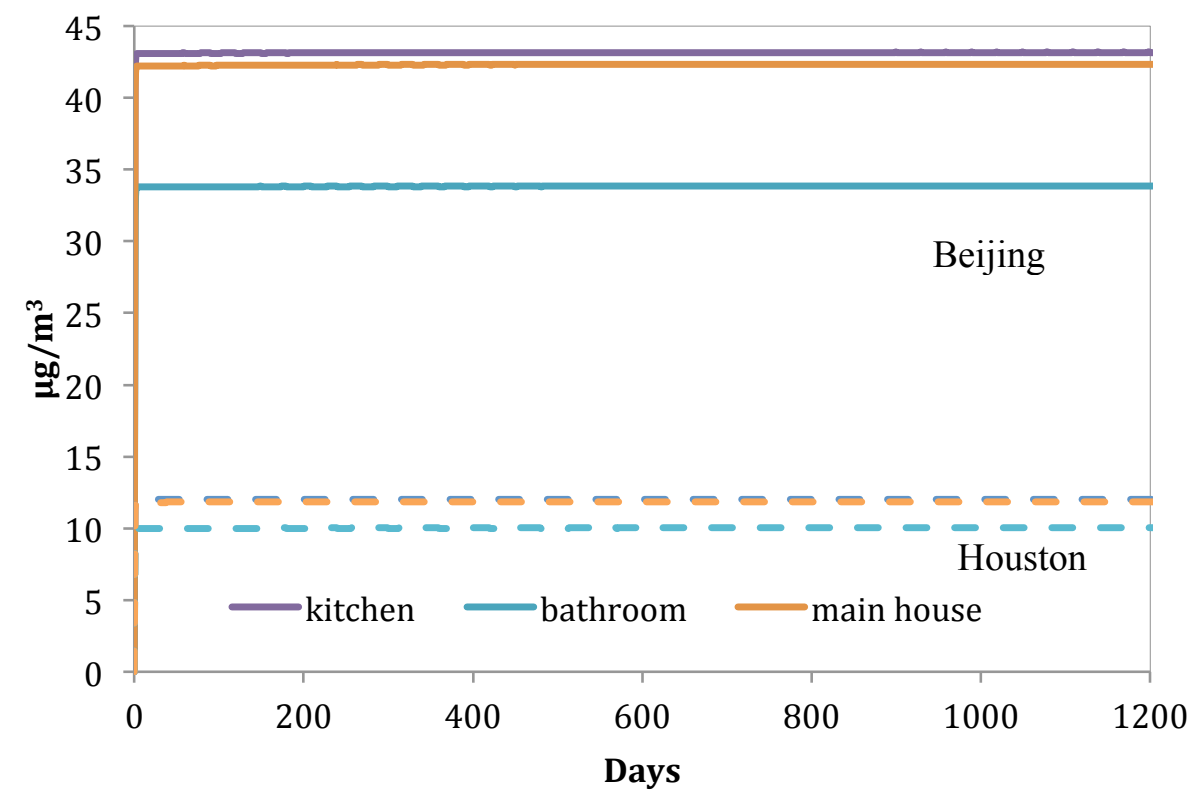

Figure 13: Indoor TSP concentrations in Houston and Beijing. 


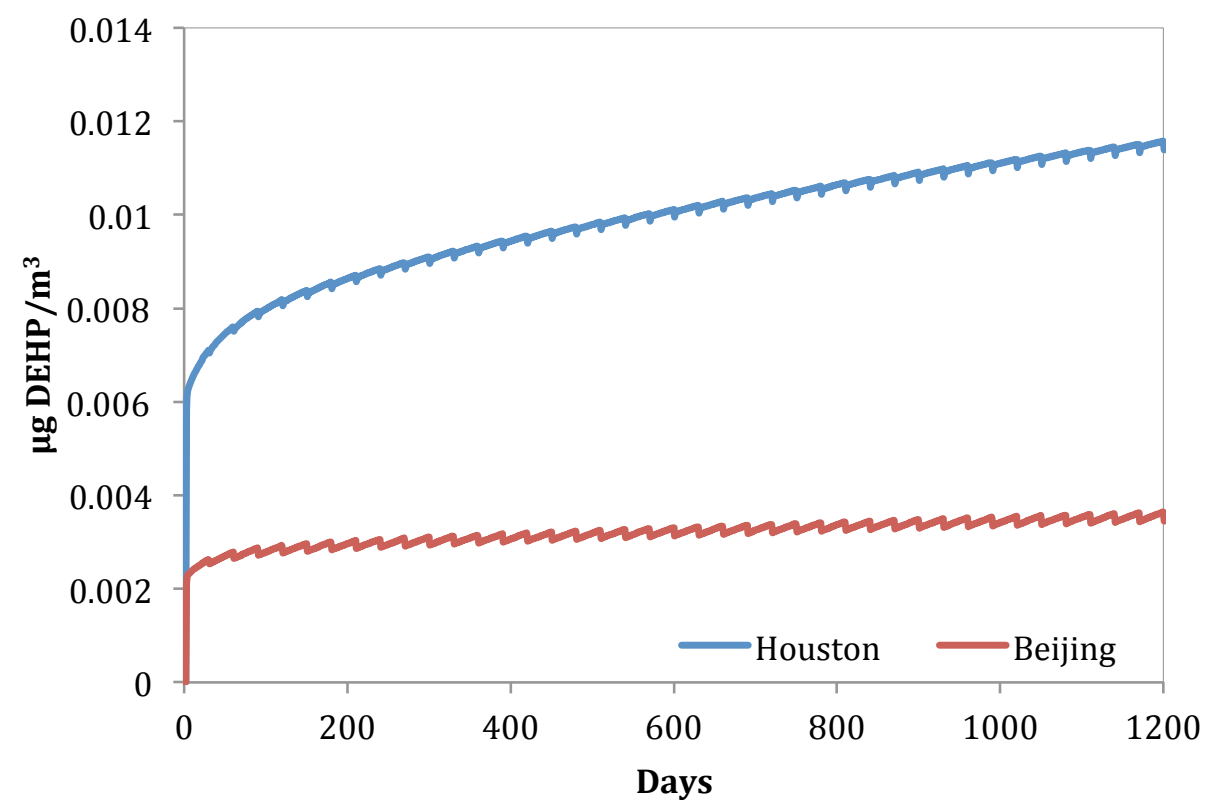

Figure 14: Gas phase DEHP concentrations in the main house in Houston and Beijing.

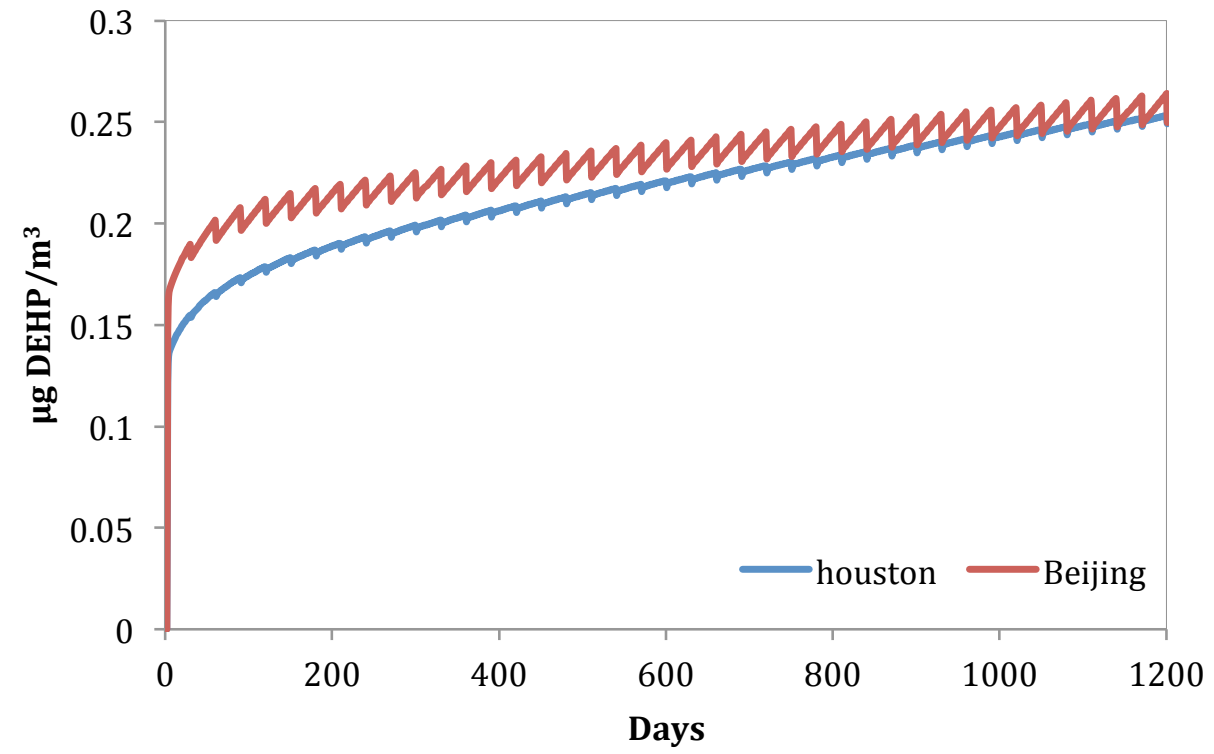

Figure 15: Airborne DEHP concentrations in the main house in Houston and Beijing. 
Figure 15 shows the airborne DEHP concentrations in the main house in both Houston and Beijing. Comparing the two curves in Figure 18 with that in Figure 14, monthly fluctuations of the two curves is even more obvious because the airborne DEHP are majorly particle-bounded. The difference of total airborne DEHP concentration is not that significant between Houston to Beijing mainly because the decrease of gas phase DEHP in Beijing was compromised by the increase of indoor TSP concentration.

\section{IMPACT OF CLEANING EFFICIENCY}

Domestic activities such as cleaning have significant influences on indoor DEHP concentrations. In most cases, cleaning removes some amount of dust loading on surfaces and keeps the level of dust loading from infinite increasing. Moreover, cleaning activity will also remove DEHP in settled dust from interior surfaces and thus have influence on the surface DEHP concentrations. In order to evaluate the impact on DEHP concentrations caused by cleaning, we altered the cleaning efficiency and compare the calculations under different cleaning conditions as shown in Table 7.

\begin{tabular}{lll}
\hline & Cleaning efficiency for & Cleaning efficiency for \\
& carpet $(\%)$ & other surfaces $(\%)$ \\
Case $11^{1}$ & 10 & 90 \\
Case 2 & 90 & 90 \\
No cleaning & 0 & 0 \\
\hline
\end{tabular}

Table 7: Cleaning conditions.

Figure 16 shows the impact of cleaning efficiency on DEHP surface concentration of carpet. With cleaning efficiency increase, the DEHP on the carpet was decreased significantly. The result is because the removed dust contains a certain amount of DEHP due to the partition effect. The higher the cleaning efficiency, the more dust-bounded

\footnotetext{
${ }^{1}$ This row represents the baseline parameters.
} 
DEHP is removed periodically. Although cleaning is also expected to affect the gas phase DEHP concentration adjacent to a sorption surface because the boundary layer may be disturbed during cleaning, we did not include this factor in the current model, but we will take into consideration in future research.

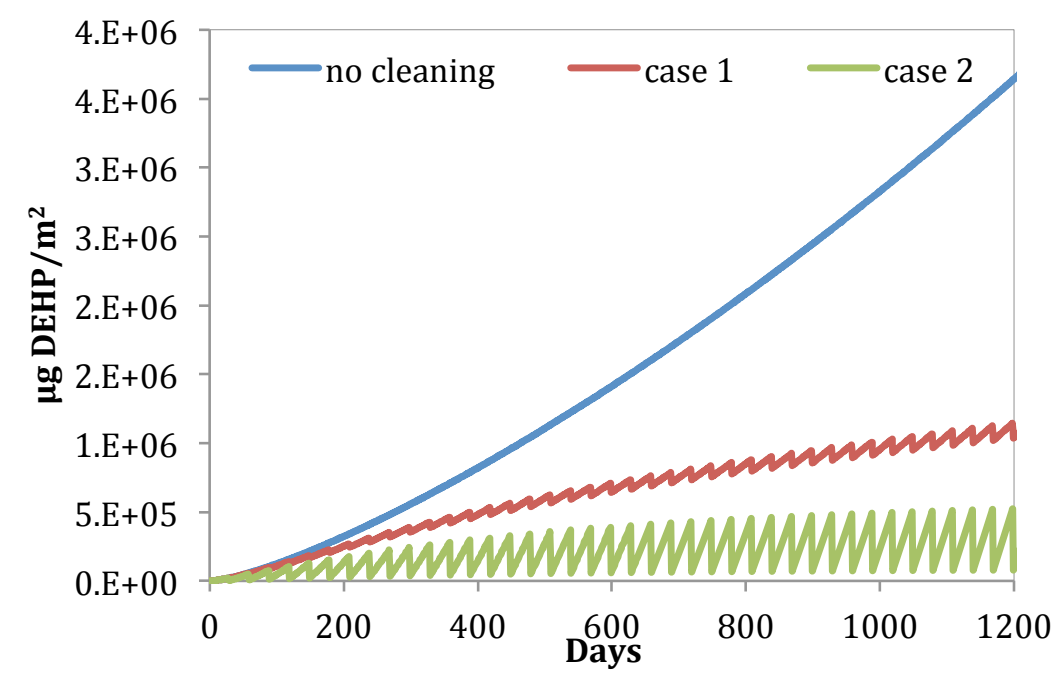

Figure 16: DEHP on the carpet under different cleaning conditions.

\section{REMOVING DEHP SOURCE AFTER A PERIOD OF TIME}

The changes of DEHP concentrations in bulk air and on surfaces are analyzed when the only source (vinyl flooring) is removed from the main house after a period of time (600 days). Figure 17 and Figure 18 show a sudden drop on gas phase and airborne DEHP concentrations after the vinyl flooring was replaced by wood floor with the same area in the main house. The sudden drop of gas phase and airborne DEHP concentrations occurred because the emission rate became zero instantly. However, in the following, the gas phase and airborne DEHP concentration decrease very slowly and present at high level for years. We believe it is because the interior surfaces and settled dust which originally behaved as indoor sinks now become as secondary sources releasing DEHP. Furthermore, Figure 19 shows clearly how the buffer effect of indoor sinks is of great 
importance to the indoor fate of phthalate. The DEHP on the wall surface in the main house was reduced and released to the bulk air after the vinyl flooring was removed, which kept the gas phase DEHP from decreasing fast. Figure 20 shows the DEHP concentration on the carpet in the main house before and after the source was removed compared with the original results.

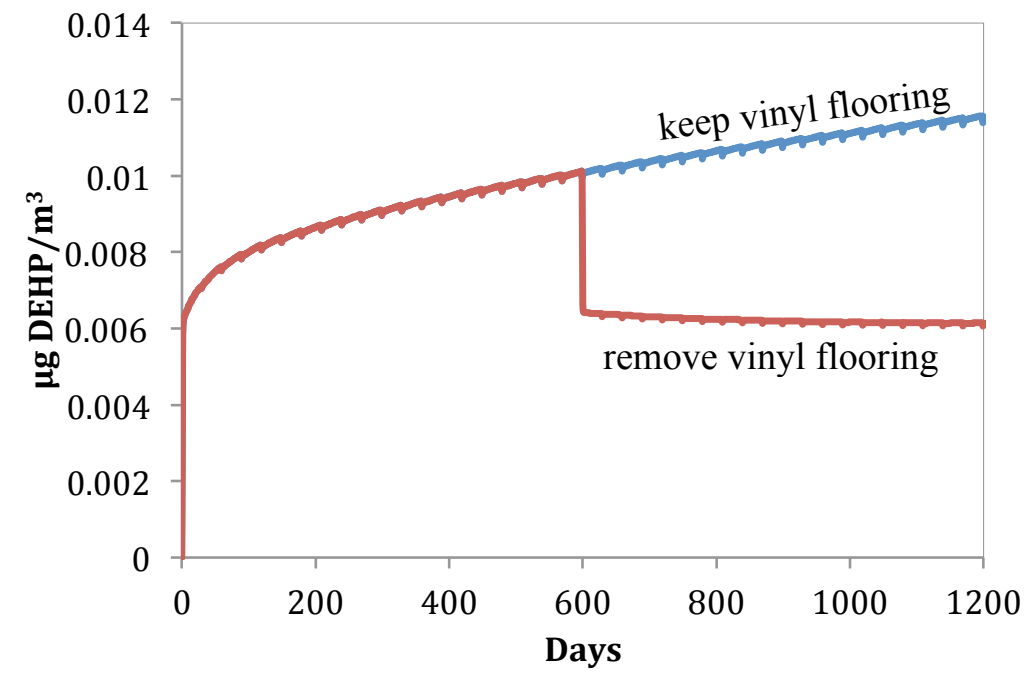

Figure 17: The gas phase DEHP concentration in the main house.

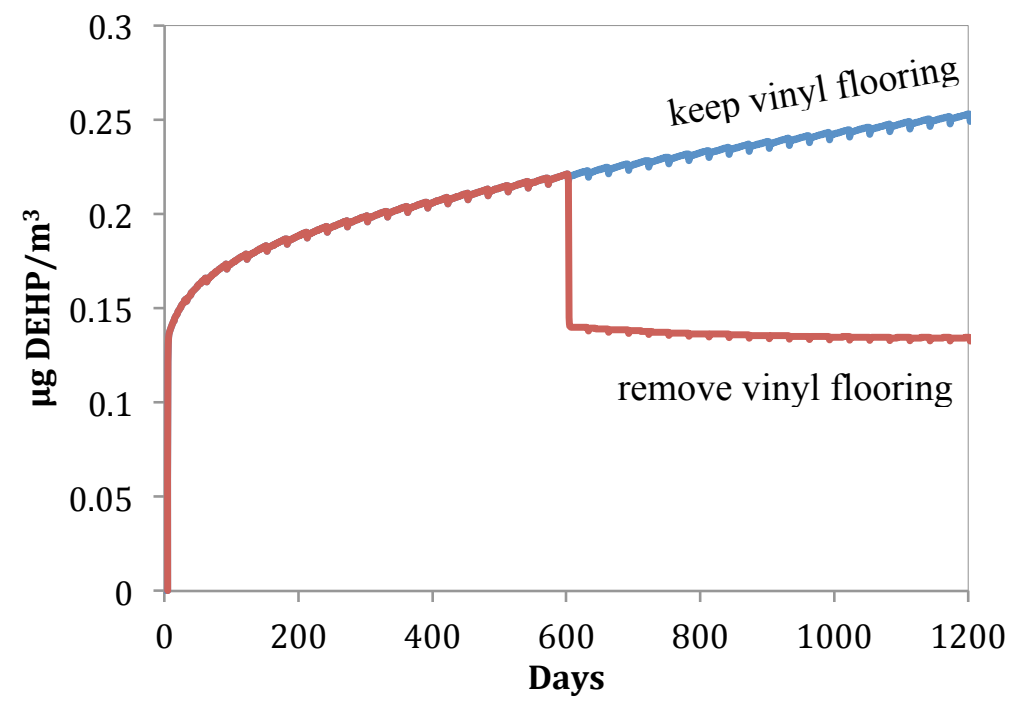

Figure 18: The airborne DEHP concentration in the main house. 


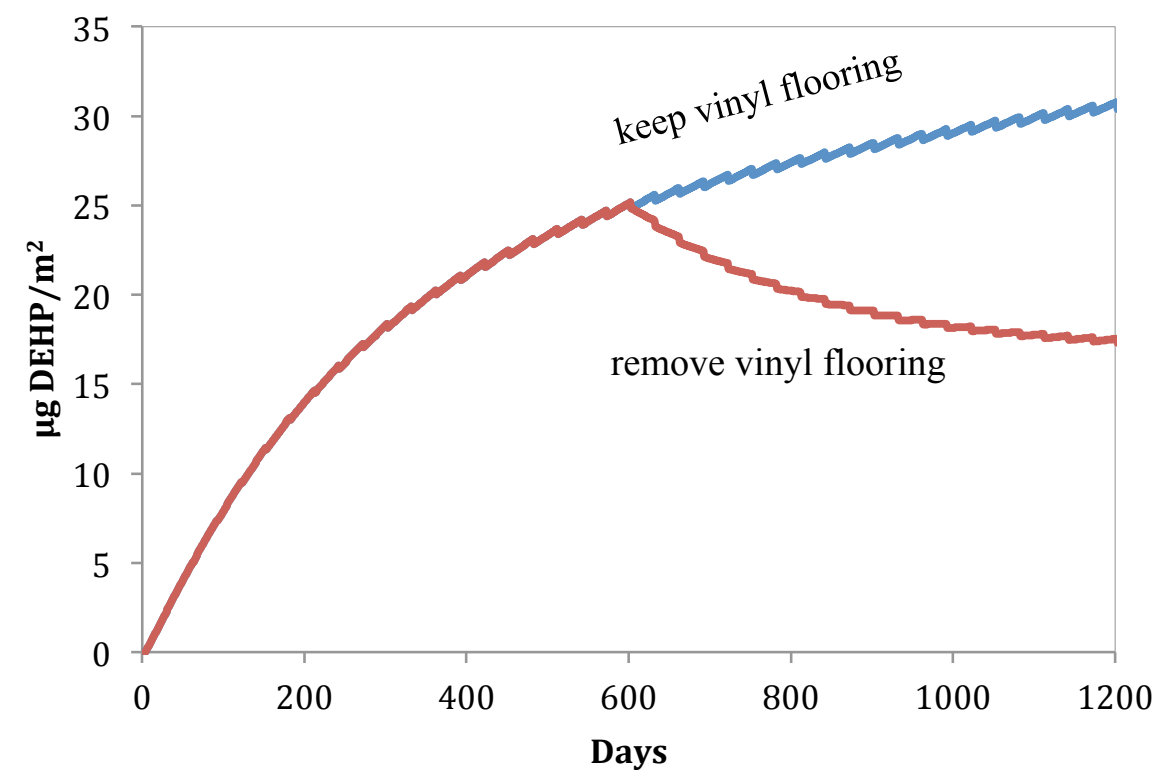

Figure 19: DEHP on the wall surface in the main house.

\section{COOKING AS AN INDOOR PARTICLE SOURCE}

As an indoor activity, cooking is a major indoor source of particles, especially fine and ultrafine particles. Table 3 gives the particle concentrations emitted from a cooking event. In this study, we incorporate the model with the daily cooking event as an important particle source. Specifically, the cooking is set to occur once a day and each single event lasts for half an hour based on people's cooking habit. As shown in Figure 20, a spike occurs as cooking emits a large amount of particles within a short time, which leads to a sharp drop in the gas phase DEHP concentration as show. The result agrees well with previous study (Xu and Little 2006). In addition, when a cooking event occurs, the airborne DEHP concentrations show even sharper increases compared to pure gas phase DEHP (Figure 21). This is mainly because the dramatic increases of particles, which will adsorb more gas phase DEHP, results in a sudden increase of airborne DEHP concentration. 


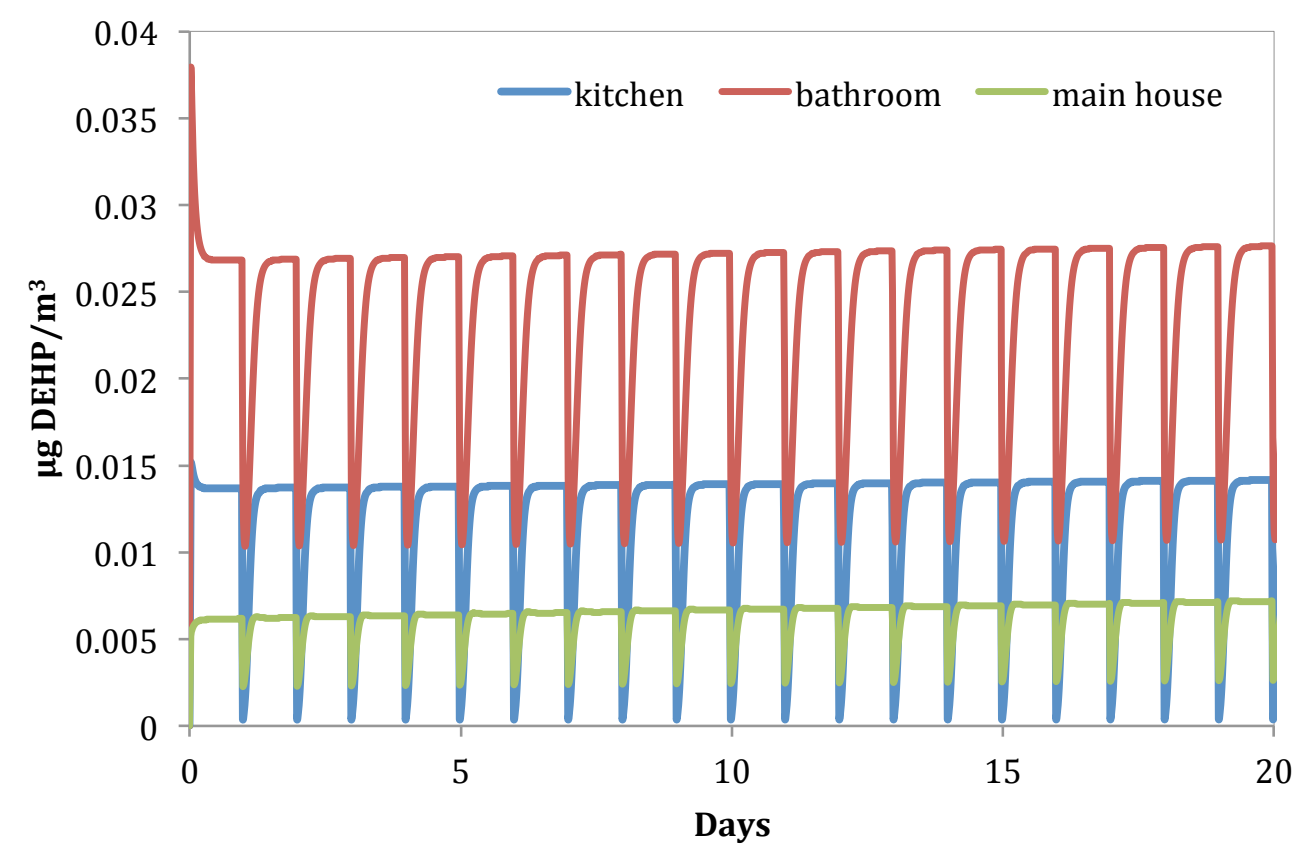

Figure 20: Gas phase DEHP concentrations in each compartment.

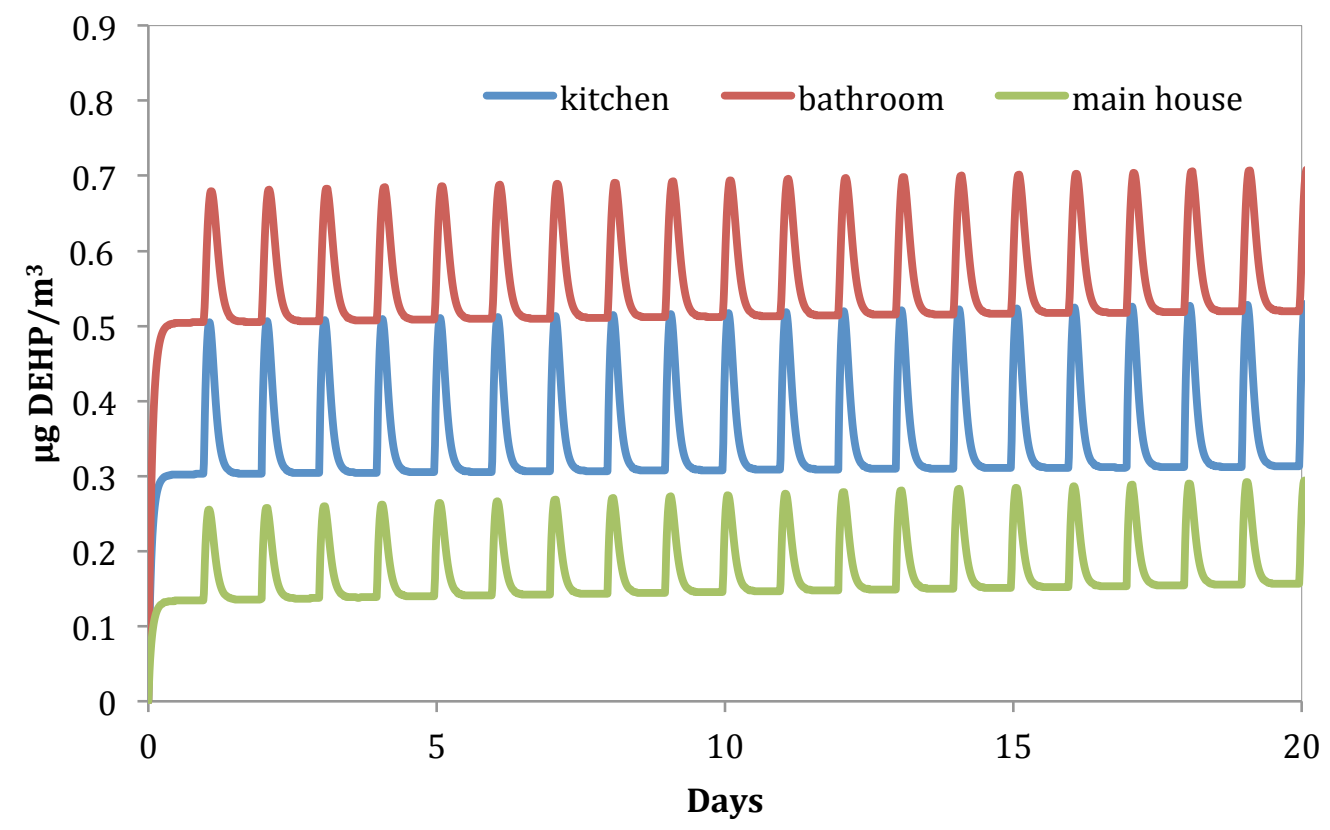

Figure 21: Airborne DEHP concentrations in each compartment. 


\section{INDOOR ENVIRONMENTAL FATES OF VARIOUS PHTHALATES}

For a given phthalate, its environmental fate is influenced by both the indoor conditions (e.g. ventilation and surface/volume ratio) and the physical and chemical properties of the compound. Therefore, in addition to DEHP, three more phthalates (DMP, BBP and DiDP) are involved in the following analysis. Their properties and the corresponding partition coefficients are listed in Table 5.

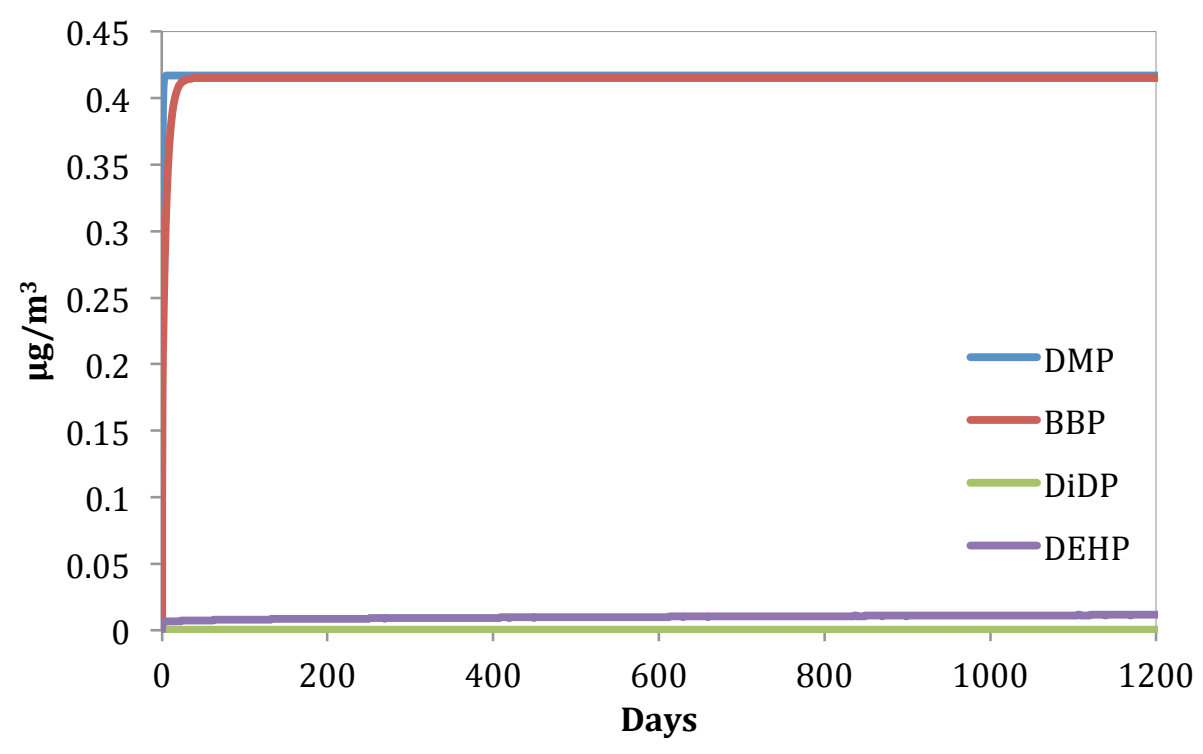

Figure 22: Gas phase SVOC concentration in the main house.

As shown in Figure 22, the gas phase concentrations of DMP and BBP are at a much higher level than that of DiDP and DEHP, though the source concentration of each phthalate is assumed the same with that of DEHP. The values of $\mathrm{K}_{\text {oa }}$ for DMP and BBP are orders of magnitude lower than that for DiDP and DEHP (Table 5), therefore the particle/air partition coefficients and dust/air partition coefficients for DMP and BBP are much smaller compared with DiDP and DEHP (Equation 8 and Equation 10). Moreover, the vapor pressure values for DMP and BBP are very high, which will result in low 
surface/air partition coefficients for the two SVOCs. Therefore, very small amount of DMP or BBP is adsorbed to interior surfaces, suspended particles or settled dust, the gas phase DMP or BBP constitutes the majority of total DMP or BBP in the environment. This explains the gas phase concentration difference between DMP (or BBP) and DiDP (or DEHP). The gas phase DiDP shown in Figure 22 is less than DEHP gas phase concentration because $K_{\text {oa }}$ value for DiDP is nearly two orders of magnitude higher than the value for DEHP, which results a greater particle/air partition coefficient (Equation 8) and therefore more DiDP is adsorbed on suspended particles.

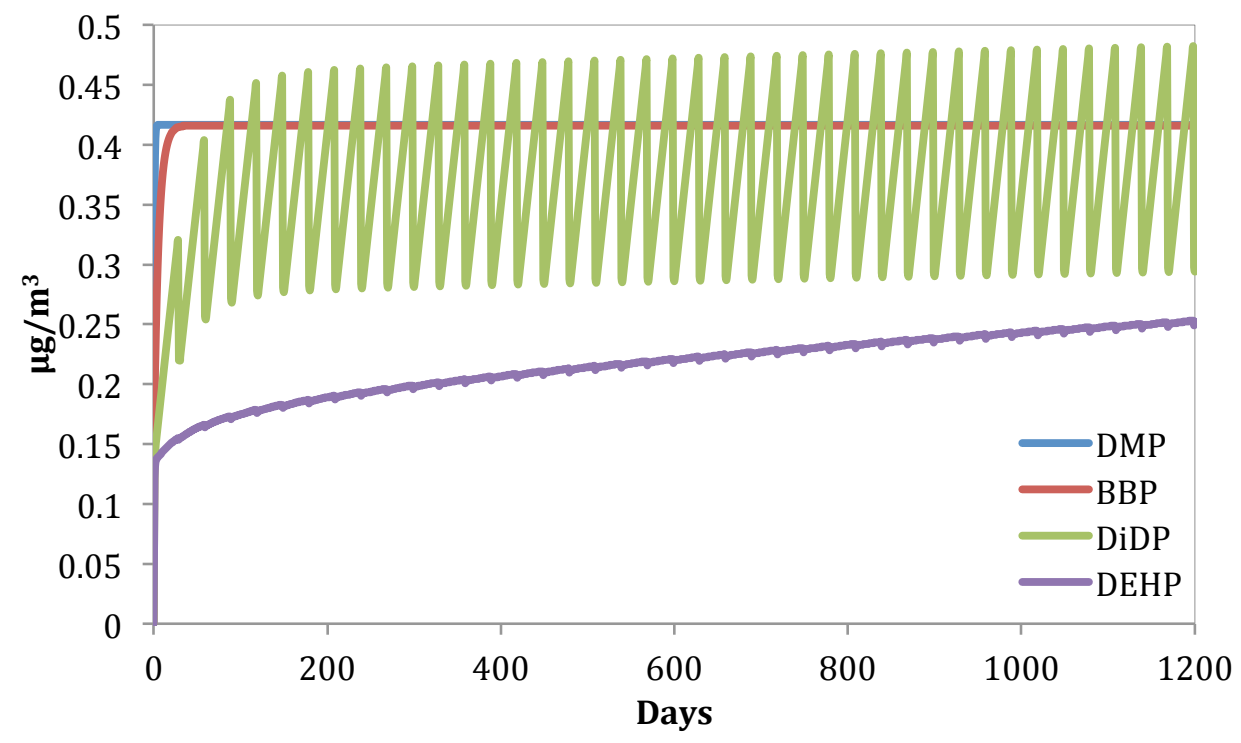

Figure 23: Airborne SVOC concentration in the main house.

Figure 23 shows the trends of airborne concentrations over time for each SVOC. Because of the relatively high volatility and small particle/air partition coefficients, airborne concentrations of DMP and BBP remained nearly unchanged compared to their gas phase concentrations. However, airborne concentrations of DiDP and DEHP subjected to considerable increase over the corresponding gas phase concentrations due 
to the large amount of particle-bounded DiDP and DEHP. In Figure 23, the airborne DiDP curve shows a strong fluctuation over time, which can be explained by DiDP's very high particle/ and dust/air partition coefficients. The resulted large dust/air partition coefficient makes the mass-fraction of DiDP in settled dust significantly higher than for DEHP and thus the airborne DiDP is greatly influenced by cleaning activities, which alter the dust loading and resuspended particles within a short time.

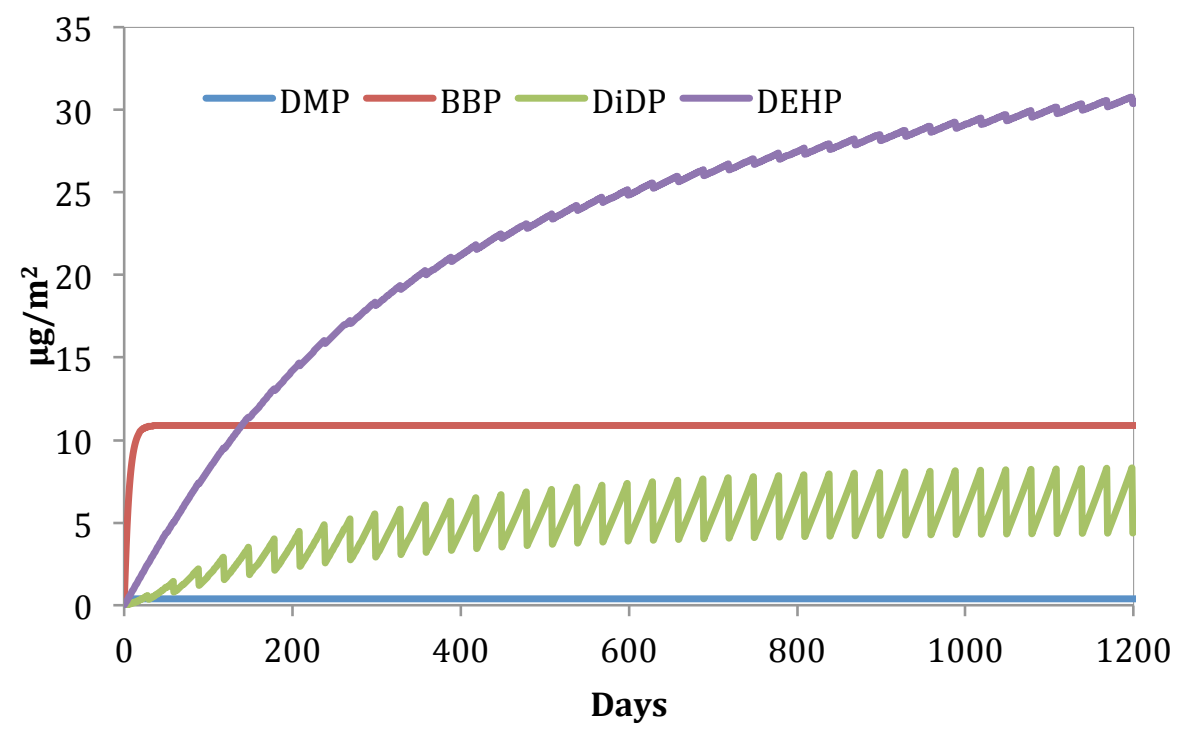

Figure 24: Surface DEHP concentration on the wall in the main house.

Figure 25 shows the surface concentrations on carpet for each phthalate in the main house. The almost-zero values of DMP and BBP are due to their high volatility and low $\mathrm{K}_{\mathrm{oa}}$ values, which then result in low surface/ and dust/air partition coefficients. Although DEHP has the lowest vapor pressure among all the SVOCs in Table 5, its $\mathrm{K}_{\text {oa }}$ value is significantly less than that of DiDP (Table 5), therefore the dust phase DEHP concentration on carpet is far less than that of DiDP. This explains the surface concentrations difference between DiDP and DEHP in Figure 25. 


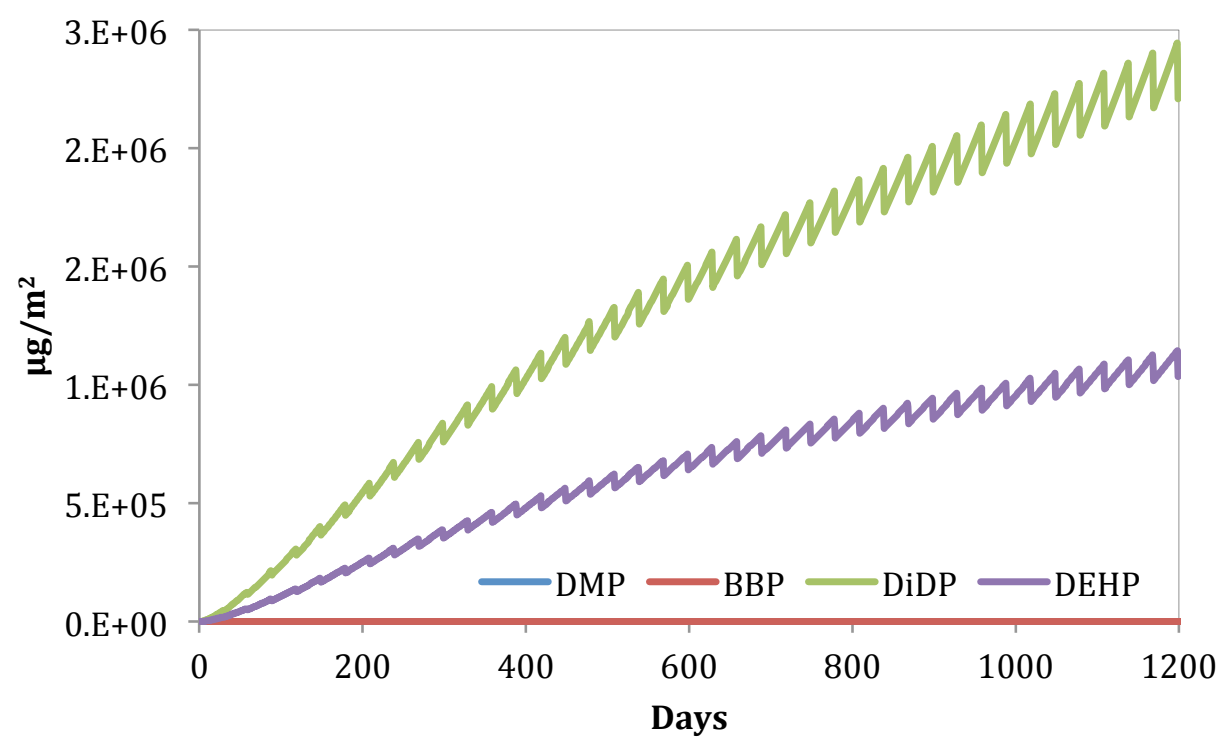

Figure 25: Surface SVOC concentration on carpet in the main house. 


\section{Chapter 4: Conclusions}

The main finding of this modeling work is that the indoor environmental fates of DEHP and other SVOCs with low vapor pressure are majorly determined by external adsorptive sinks, which include suspended particles, interior surfaces (ceiling, wall, carpet, wood floor, furniture, window and tile) and settled dust. Air exchange rate and the ratio of SVOC's source emission area to adsorptive surface area have impacts on SVOC's gas phase concentration to some extend. As modeled in two locations (Houston and Beijing) with different outdoor particle levels in this three-compartment residential house, the dynamic indoor particle predictions show a substantial influence of TSP concentration on gas phase and airborne DEHP level: suspended particle-bounded DEHP constitutes over $90 \%$ of the total airborne DEHP. Particle movement (deposition and resuspension) has impacts on airborne and dust-bounded DEHP in two ways: 1) deposition of particles transfers particle-bounded DEHP onto various interior surfaces and 2) resuspension from settled dust causes increase of airborne DEHP amounts. Domestic activities included in the model (cooking and cleaning) are shown to have significant effects on airborne and surface phase DEHP concentrations. Cooking events can introduce considerably high level of fine particles within a short time and therefore reduce gas phase DEHP by over $70 \%$ depending on the original gas phase level while increase airborne DEHP by 20 - 60\% simultaneously within the same time period. Model predictions involving cleaning show that removal of settled dust by cleaning reduces DEHP level on various interior surfaces significantly depending on the cleaning efficiency. By replacing the DEHP source with another non-source material after a period of time, the model shows the buffer effect of adsorptive sinks, which become secondary sources afterwards and release adsorbed DEHP into the indoor air and thus 
keep the gas phase and airborne DEHP concentrations at high level. Lastly, the characteristics of SVOCs have been included in the model and the results show SVOC's vapor pressure and octanol/air partition coefficients have great impacts on gas phase and airborne SVOC concentration by determining surface/, particle/ and dust/air partition coefficients. 


\section{Nomenclature}

$\mathrm{V}_{\mathrm{i}}$ - volume of the $\mathrm{i}^{\text {th }}$ compartment in the house, $\mathrm{m}^{3}$.

$\mathrm{TSP}_{\mathrm{i}}-$ total suspended particle concentration in the $\mathrm{i}^{\text {th }}$ compartment in the house, $\mu \mathrm{g} / \mathrm{m}^{3}$.

$\mathrm{TSP}_{\text {outdoor }}-$ outdoor total suspended particle concentration, $\mu \mathrm{g} / \mathrm{m}^{3}$.

$\mathrm{Q}_{\mathrm{oi}}-$ ventilation rate from outdoor to the $\mathrm{i}^{\mathrm{th}}$ compartment, $\mathrm{m}^{3} / \mathrm{hr}$.

$\operatorname{TSP}_{n}$-particle concentration for the particles with the $\mathrm{n}^{\text {th }}$ size fraction, $\mu \mathrm{g} / \mathrm{m}^{3}$.

$\mathrm{Q}_{\mathrm{ij}}$ - ventilation rate from the $\mathrm{i}^{\text {th }}$ compartment to the $\mathrm{j}^{\text {th }}$ compartment, $\mathrm{m}^{3} / \mathrm{hr}$.

$\mathrm{P}_{\mathrm{o}}$ - penetration rate for outdoor particles through building envelop, unitless.

$V_{i}-$ volume of the $i^{\text {th }}$ compartment in the house, $\mathrm{m}^{3}$.

$\overline{v_{d_{k}}}$ - average deposition velocity for particle deposition onto the $\mathrm{k}^{\text {th }}$ interior surface,

$\mathrm{m} / \mathrm{hr}$.

$\mathrm{v}_{\mathrm{d}, \mathrm{n}}-$ deposition velocity for the particles with the $\mathrm{n}^{\text {th }}$ size fraction, $\mathrm{m} / \mathrm{hr}$.

$\mathrm{A}_{\mathrm{k}}$ - surface area of the $\mathrm{k}^{\mathrm{th}}$ interior surface in the house, $\mathrm{m}^{2}$.

$\mathrm{R}_{\mathrm{k}}$ - particle resuspension rate from the $\mathrm{k}^{\text {th }}$ interior surface in the house, $\mathrm{hr}^{-1}$.

$M_{k}$ - dust loading on the $\mathrm{k}^{\text {th }}$ interior surface in the house, $\mu \mathrm{g} / \mathrm{m}^{2}$.

$\mathrm{S}_{\mathrm{i}}$ - indoor particle source in the $\mathrm{i}^{\text {th }}$ compartment in the house, $\mu \mathrm{g} / \mathrm{hr}^{-1}$.

$y_{i}-$ gas phase DEHP concentration in the $i^{\text {th }}$ compartment in the house, $\mu \mathrm{g} / \mathrm{m}^{3}$.

$\mathrm{F}_{\mathrm{i}}$ - airborne particle-bounded DEHP concentration in the $\mathrm{i}^{\text {th }}$ compartment in the house, $\mu \mathrm{g} / \mathrm{m}^{3}$.

$\mathrm{y}_{\text {outdoor }}-$ outdoor gas phase DEHP concentration, $\mu \mathrm{g} / \mathrm{m}^{3}$.

$\mathrm{y}_{0}-$ gas phase DEHP concentration in the boundary layer immediately adjacent to vinyl flooring, $\mu \mathrm{g} / \mathrm{m}^{3}$. 
$\mathrm{C}_{0}-$ material phase DEHP concentration in the vinyl flooring, $\mu \mathrm{g} / \mathrm{m}^{3}$.

$\mathrm{F}_{\text {outdoor }}$ - outdoor airborne particle-bounded DEHP concentration, $\mu \mathrm{g} / \mathrm{m}^{3}$.

$\mathrm{h}_{\mathrm{m}, \mathrm{k}}-$ mass transfer coefficient for DEHP above the $\mathrm{k}^{\text {th }}$ interior surface in the house, $\mathrm{m} / \mathrm{hr}$.

$y_{0, \text { surf }_{k}}-$ gas phase DEHP concentration in the boundary layer immediately adjacent to the $\mathrm{k}^{\text {th }}$ interior surface in the house, $\mu \mathrm{g} / \mathrm{m}^{3}$.

$X_{\text {dust }_{k}}$ - mass-fraction of DEHP in settled dust on the $\mathrm{k}^{\text {th }}$ interior surface, $\mu \mathrm{g}$ DEHP $/ \mu \mathrm{g}$

particle.

$\dot{m}(t)$ - DEHP emission rate from vinyl flooring, $\mu \mathrm{g} /\left(\mathrm{m}^{3} \mathrm{hr}\right)$.

$\mathrm{K}$ - material-air partition coefficient for a given SVOC, unitless.

$\mathrm{K}_{\mathrm{pg}}$ - particle-air partition coefficient for a given $\mathrm{SVOC}, \mathrm{m}^{3} / \mu \mathrm{g}$ particle.

$\mathrm{K}_{\mathrm{dg}}$ - dust-gas partition coefficient for a given SVOC, $\mathrm{m}^{3} / \mu \mathrm{g}$ particle.

$\mathrm{f}_{\text {om_part }}-$ the fraction of suspended particles that is organic matter, unitless.

$\mathrm{f}_{\text {om_dust }}-$ the fraction of settled dust that is organic matter, unitless.

$\mathrm{K}_{\mathrm{oa}}$ - the octanol/air partition coefficient, unitless.

$\varrho_{\text {part }}-$ density of suspended particles, $\mu \mathrm{g}$ dust $/ \mathrm{m}^{3}$.

$\varrho_{\text {dust }}-$ density of settled dust, $\mu \mathrm{g}$ dust $/ \mathrm{m}^{3}$.

$\mathrm{C}_{\text {surf }}$ - the SVOC concentration on surface, $\mu \mathrm{g} / \mathrm{m}^{2}$.

$\mathrm{K}_{\text {surf }}$ - surface-air partition coefficient for a given SVOC, $\mathrm{m}$.

$\varepsilon$ - the porosity of the building material (in this study, carpet), unitless.

$\mathrm{K}_{\mathrm{s}}$ - gas-fiber partition coefficient of phthalate, unitless.

$\mathrm{M}_{\mathrm{ca}}$ - the average dust concentration in the carpet, $\mu \mathrm{g}$ particle $/ \mathrm{m}^{3}$. 
$C_{g}$ - gas-phase phthalate concentration in the carpet, $\mu \mathrm{g} / \mathrm{m}^{3}$.

$D_{s}-$ diffusion coefficient of phthalates within the carpet fibers, $\mathrm{m}^{2} / \mathrm{h}$.

$\mathrm{D}_{\mathrm{ia}}-$ diffusion coefficient of phthalates in air, $\mathrm{m}^{2} / \mathrm{h}$. 


\section{References}

Axley, J. W. 1991. Adsorption modeling for building contaminant dispersal analysis. Indoor Air 2, 147-171.

Bennett, D. H. and Furtaw, E. J. 2004. Fugacity-Based Indoor residential Pesticide Fate Model. Environmental Science and Technology. 38, 2142-2152.

Bornehag, C., Lundgren, B., Weschler, C. J., Sigsgaard, T., Hagerhed-Engman, L. and Sundell, J. 2005. Phthalates in Indoor Dust and Their Association with Building Characteristics. Environmental Health Perspectives V. 113, No. 10, 1399-1404.

Bornehag, C. and Nanberg, E. 2010. Phthalate exposure and asthma in children. International Journal of andrology 33, 333-345.

Cadogan, D. F. and Howick, C. J. 1996. Plasticizers. Kirk-Othmer Encyclopedia of Chemical Technology, Vol. 19. New York: John Wiley and Sons, 258-290.

Chen, C., Wu, P. and Chung, Y. 2009. Coupled biological and photo-Fenton pretreatment system for the removal of di-(2-ethylhexyl) phthalate (DEHP) from water. Bioresource Technology 100, 4531-4534.

Clausen, P. A., Hansen, V., Gunnarsen, L., Afshari, A. and Wolkoff, P. 2004. Emission of Di-2-ethylhexyl Phthalate from PVC Flooring into Air and Uptake in Dust: Emission and Sorption Experiments in FLEC and CLIMPAQ. Environmental Science and Technology 38, 2531-2537.

Cox, S. S., Hdgson, A. T., Little, J. C. 2001. Measuring concentrations of volatile organic compounds in vinyl flooring. Journal of the Air and Waste Management Association 51, 1195-1201.

Deng, Q., Yang, X., Zhang, J. 2009. Study on a new correlation between diffusion coefficient and temperature in porous building materials. Atmospheric Environment 43, 2080-2083.

Fromme, H., Albrecht, M., Angerer, J., Drexler, H., Gruber, L., Schlummer, M. et al. 2007. Integrated Exposure Assessment Survey (INES) exposure to persistent and bioaccumulative chemicals in Bavaria, Germany. International Journal of Hygiene and Environmental Health 210(3-4): 345-349.

Haghighat, F., Huang, H., Lee, C. S. 2005. Modeling approaches for indoor air VOC emissions from dry building materials - A review. ASHRAE Transactions 111, 635-645.

Heudorf, U., Mersch-Sundermann, V., et al., 2007. Phthalates: toxicology and exposure. International journal of Hygiene and Environmental Health 210 (5), 623-634.

Hodgson, A. T., Ming, K. Y., Singer, B. C. 2005. Quantifying Object and Material Surface Areas in Residences. Available: http:// repositories.cdlib.org/lbnl/LBNL56786 [accessed 1 December 2010]. 
Huang, J. M., Chen, Q., Ribot, B., Rivoalen, H. 2004. Modeling contaminant exposure in a singlefamily house. Indoor Built Environment 13, 5-19.

Hunt, A., Johnson, D. L., Watt, J. M., Thornton, I. 1992. Characterizing the sources of particulate lead in house dust by automated scanning electron microscopy. Environmental Science and Technology 26, 1513-1523.

Jaakkola, J. K. and Knight, T. L. 2008. The Role of Exposure to Phthalates from Polyvinyl Chloride Products in the Development of Asthma and Allergies: A Systematic Review and Meta-analysis. Environmental Health perspectives Vol. 116 , No. 7, 845-853.

Kato, K., Silva, M., Reidy, J., Hurtz, D. I., Malek, N., Needham, L. 2004. Mono(2-ethyl5-hydroxyhexyl) phthalate and mono-(2-eth-yl-5-oxohexyl) phthalate as biomarkers for human expo- sure assessment to di-(2-ethylhexyl) phthalate. Environmental Health Perspectives 112: 327-330.

Koch, H. M., Drexler, H., Angerer, J. 2003. An estimation of the daily intake of di(2ethylhexyl)phthalate (DEHP) and other phthalates in the general population. Int $\mathbf{J}$ Hyg Environ Health. 206(2): 77-83.

Kolarik, B., Naydenov, K., et al., 2008. The association between phthalates in dust and allergic diseases among Bulgarian children. Environmental Health Perspectives $116(1), 98-103$.

Latini, G., Felice, C. D. and Verrotti, A. 2004. Plasticizers, infant nutrituion and reproductive health. Reproductive Toxicology 19, 27-33.

Liu, C., Zhao, B. and Zhang, Y. 2010. The influence of aerosol dynamics on indoor exposure to airborne DEHP. Atmospheric Environment. 44, 1952-1959.

Liu, D. and Nazaroff, W. W. 2001. Modeling pollutant penetration across building envelops. Atmospheric Environment 35, 4451-4462.

Matsumoto, M., Hirata-Koizumi, M. and Ema, M. 2008. Potential adverse effects of phthalic acid esters on human health: A review of recent studies on reproduction. Regulatory Toxicology and Pharmacology. 50, 37-49.

McKee, R. H., Butala, J. H. David, R. M. and Gans, G. 2004. NTP center for the evaluation of risks to human reproduction reports on phthalates: addressing the data gaps. Reproductive Toxicology 18, 1-22.

Morawska, L. and Salthammer, T. (Eds.), 2003. Indoor Environment - Airborne Particles and Settled Dust. Wiley-VCH, Weinheim.

Oie, L., Hersoug, L. G., Madsen, J. O. 1997. Residential exposure to plasticizers and its possible role in the pathogenesis of asthma. Environmental Health Perspectives 105: 972-978. 
Polidori, A., Turpin, B. et al. 2006. Fine organic particulate matter dominates indoorgenerated $\mathrm{PM}_{2.5}$ in RIOPA homes. Journal of exposure science \& environmental epidemiology. 16, 321-31.

Riley, W. J., McKone, T. E., Lai, A. C. K. and Nazaroff, W. W. 2002. Indoor Particulate Matter of Outdoor Origin: Importance of Size-Dependent Removal Mechanisms. Environmental Science and Technology. 36, 200-207.

Rudel, R. A., Camann, D. E., Spengler, J. D., Korn, L. R. and Brody, J. G. 2003. Phthalates, alkylphenols, pesticides, polybrominated diphenyl ethers, and other endocrine-disrupting compounds in indoor air and dust. Environmental Science and Technology 37: 4543-4553.

Rudel, R. A., Perovich, L. J. 2009. Endocrine disrupting chemicals in indoor and outdoor air. Atmospheric Environment 43, 170-181.

Stapleton, H. M., Klosterhaus, S., Eagle, S., Fuh, J., Meeker, J. D., Blum, A. and Webster, T. F. 2009. Detection of Organophosphate Flame Retardants in Furniture Foam and U.S. House Dust. Environmental Science and Technology 43, 7490-7395.

SRI. 2007. Plasticizer CEH Report.

Thatcher, T. L., Layton, D. W. 1995. Deposition, resuspension, and penetration of particles within a residence. Atmospheric Environment 29, 1487-1497.

Turpin, B. J., Lim, H. J. 2001. Species contributions to $\mathrm{PM}_{2.5}$ mass concentrations: revisiting common assumptions for estimating organic mass. Aerosol Science and Technology 35, 602-610.

Uhde, E., Bennarek, M., Fuhrmann, F. and Salthammer, T. 2001. Phthalic Esters in the Indoor Environment-Test Chambers Studies on PVC-Coated Wallcoverings. Indoor Air 11, 150-155.

U.S. EPA. 2005. A Pilot Study of Children's Total Exposure to Persistent Pesticides and Other Persistent Organic Pollutants (CTEPP). Available: http://www.epa.gov/heasd/ctepp/ctepp_report.pdf [accessed 1 December 2010].

Weschler, C. J. 2003. Indoor/outdoor connections exemplified by processes that depend on an organic compound's saturation vapor pressure. Atmospheric Environment $37,5455-5465$.

Weschler, C. J. and Nazaroff, W. W. 2008. Semivolatile organic compounds in indoor environments. Atmospheric Environment 42, 9018-9040.

Weschler, C. J. 2009. Changes in indoor pollutants since the 1950s. Atmospheric Environment 43, 153-169.

Weschler, C. J. and Nazaroff, W. W. 2010. SVOC partitioning between the gas phase and settled dust indoors. Atmospheric Environment 44, 3609-3620. 
Wilkes, C. R., Small, M. J., Andelman, J. B., Giardino, N. J., Marshall, J. 1992. Inhalation exposure model for volatile chemicals from indoor uses of water. Atmospheric Environment 26(12), 2227-2236.

Xiong, J., Zhang, Y., Wang, X., Chang, D. 2008. Macro-meso two-scale model for predicting the VOC diffusion coefficients and emission characteristics of porous building materials. Atmospheric Environment 42(21), 5278-5290.

Xu, Y. and Little, J. C. 2006. Predicting Emissions of SVOCs from Polymeric Materials and Their Interaction with Airborne Particles. Environmental Science and Technology 40, 456-461.

Xu, Y., Hubal, E. A., Clausen, P. A. and Little J. C. 2009. Predicting Residential Exposure to Phthalate Plasticizer Emitted from Vinyl Flooring: A Mechanistic Analysis. Environmental Science and Technology 43.2374-2380.

Xu, Y., Hubal, E. A. and Little, J. C. 2010. Predicting Residential Exposure to Phalate Plasticizer Emitted from Vinyl Flooring: Sensitivity, Uncertainty and Implications for Biomonitering. Environmental Health Perspectives Vol. 118, No. 2, 253-258.

Zhang, X., Diamond, M. L., Ibarra, C., Harrad, S. 2009. Multimedia Modeling of Polybrominated Diphenyl Ether Emissions and Fate Indoors. Environmental Science and Technology 43, 2845-50. 


\section{Vita}

Yirui Liang was born in Hunan Province, China. He went to Tsinghua University in Beijing, P.R.C. and received the degree of Bachelor of Science in June 2009. During the summer of 2008, he volunteered in the National Aquatics Center (a.k.a. Water Cube) in Beijing for the Games of XXIX Olympiad. In 2009, Yirui Liang entered the Graduate School at the University of Texas at Austin. He finished his master's degree in December 2010.

Permanent email: liangyirui@gmail.com

This thesis was typed by Yirui Liang. 